\title{
Multi-Domain and Multi-Material Topology Optimization in Design and Strengthening of Innovative Sustainable Structures
}

\author{
Katarzyna Tajs-Zielińska *(D) and Bogdan Bochenek (D) \\ Faculty of Mechanical Engineering, Cracow University of Technology, al. Jana Pawla II 37, \\ 31-864 Krakow, Poland; Bogdan.Bochenek@pk.edu.pl \\ * Correspondence: Katarzyna.Tajs-Zielinska@pk.edu.pl; Tel.: +48-695-226-488
}

Citation: Tajs-Zielińska, K.; Bochenek, B. Multi-Domain and Multi-Material Topology Optimization in Design and Strengthening of Innovative Sustainable Structures. Sustainability 2021, 13, 3435. https://doi.org/ $10.3390 /$ su13063435

Academic Editor: Changbum R. Ahn

Received: 8 February 2021

Accepted: 17 March 2021

Published: 19 March 2021

Publisher's Note: MDPI stays neutral with regard to jurisdictional claims in published maps and institutional affiliations.

Copyright: (c) 2021 by the authors. Licensee MDPI, Basel, Switzerland. This article is an open access article distributed under the terms and conditions of the Creative Commons Attribution (CC BY) license (https:// creativecommons.org/licenses/by/ $4.0 /)$.

\begin{abstract}
Expectations and challenges of modern sustainable engineering and architecture stimulate intensive development of structural analysis and design techniques. Designing durable, light and eco-friendly constructions starts at the conceptual stage, where new efficient design and optimization tools need to be implemented. Innovative methods, like topology optimization, become more often a daily practice of engineers and architects in the process of solving more and more demanding up-to-date engineering problems efficiently. Topology optimization is a dynamically developing research area with numerous applications to many research and engineering fields, ranging from the mechanical industry, through civil engineering to architecture. The motivation behind the present study is to make an attempt to broaden the area of topology optimization applications by presenting an original approach regarding the implementation of the multi-domain and multi-material topology optimization to the design and the strengthening/retrofitting of structures. Moreover, the implementation of the design-dependent self-weight loading into the design model is taken into account as a significantly important issue, since it influences the final results of the topology optimization process, especially when considering massive engineering structures. As an optimization tool, the original efficient heuristic algorithm based on Cellular Automata concept is utilized.
\end{abstract}

Keywords: topology optimization; structure strengthening; multi-material structure; self-weight; Cellular Automata

\section{Introduction}

Observed for decades, the continuous and intensive development of industry and construction has led to both positive and negative changes in the many areas of human life. Nowadays, the efforts of scientists, engineers, architects and planners are focused on building innovative sustainable architecture restoring the balance between the products of human hands and nature as nature is thought to have created the best environment for humans. To achieve the goal, architecture, urban planning, civil engineering, material science, computer science and mechanical engineering cooperate to make good designs that can improve the quality of life. As a result of this cooperation, new innovative and efficient design methods are developed, which can combine aesthetics and ecology with reasonable engineering requirements and limitations of economy.

Among innovative design tools, topology optimization took its place as an important approach, soon after it was introduced in [1]. This powerful and versatile approach allows original designs to be created by an optimal distribution of material within the design space. At the same time, over the last decades, one could observe the implementation of various specific topology optimization methods, ranging from gradient-based approaches, e.g., [1-4], where mathematical models are derived to calculate the sensitivities of design variables, to non-gradient-based ones, where material is redistributed using various, in many cases heuristic, techniques. In what follows, generation of optimal topologies involves, among others, Evolutionary Structural Optimisation (ESO) and Bi-Directional Evolutionary Structural Optimization (BESO), e.g., [5,6]; genetic algorithms, e.g., [7,8]; other 
biologically inspired algorithms, e.g., [9,10]; the material cloud method, e.g., [11]; splinebased topology optimization, e.g., [12]; the level set method, e.g., [13-16]; proportional topology optimization [17]; or moving morphable components approach, e.g., [18,19].

The most recent development is observed when coupling the Solid Isotropic Material with Penalisation (SIMP) approach with the Non-Uniform Rational Basis Spline (NURBS) hyper-surfaces framework. The robustness and effectiveness of the SIMP method combined with the NURBS entities provide a pure geometrical (CAD-compatible) descriptor of the topology of the continuum. The isogeometric topology optimization method [20-22] has recently been used to solve problems involving requirements on structural displacements and eigenfrequencies, as well as in multi-scale topology optimization problems. A variant of this method has also been used for the multi-material topology optimization of continuum structures [23].

Many survey papers and books provide broad discussions on topology optimization concepts, e.g., [24-26] or [27]. At the same time, hundreds of papers present numerous results obtained for both simple models and complicated engineering structures. Nevertheless, although remarkable achievements have been already made, there is still room for further investigations.

Topology optimization has been broadly accepted by the design community, and literature presents various civil engineering and architectural applications like designing bridges, e.g., [28,29]; designing high-rise buildings, e.g., [30]; and others e.g., [31]. The discussion regards various issues including, for example, different types of constraints [32] and the optimization of bi-material structures [33]. The strengthening of civil structures suffering from the effects of material degradation, an extension of the standard area of application of topology optimization, was proposed as well. This very important and up-to-date topic of retrofitting heritage structures has been reported in the literature and $[34,35]$ may serve here as examples. Topology optimization allows original designs to be obtained for civil engineering and architectural structures and can complement, for example, tensegrity designs [36,37].

This paper proposes an original insight into the development of design and strengthening of civil structures within innovative sustainable architecture by introducing a heuristic approach to multi-material topology optimization, which can be performed for specially arranged structural sub-domains for which different materials are implemented. Once the design domain has been divided into sub-regions, optimal topologies are generated under the restriction that the redistribution of material can be performed only within sub-domains selected for the employed materials. This approach is an alternative to the standard one, which is the redistribution of one or a few materials within the whole design domain.

The presented concept is completed by including self-weight loading, which makes obtained solutions more practical and realistic. Topology optimization of structures under design-dependent load is rather rarely considered in the literature. The first consideration of self-weight loading in optimal design can be found in [38], one of the first applications of topology optimization to structures under self-weight loading is discussed in [39], and some architectural applications can be also found in, e.g., [40]. The implementation of the self-weight loading has a significant influence on the final results of topology optimization process, which is very important, especially when dealing with the optimization of massive engineering structures, like, for example, bridges or carrying systems of tall buildings. The nature of the design-dependent loading is that the location, direction and magnitude of the load depend on the actual shape of the structure. Among examples, one can point out surface pressure caused by wind loads, e.g., [41]. Topology optimization of structures under design-dependent loads can be a challenging task because it cannot be treated as an extension of standard formulation of topology optimization under fixed loads and therefore requires a modification of well-recognized approaches in order to eliminate issues like a non-monotonous behavior of the compliance or parasitic effect [1].

The outline of the paper is as follows. In Section 2, the topology optimization problem is formulated, and the concept of sub-domain-based optimization is described. The Cellular 
Automata topology generator is introduced in Section 3, where local update rules and the flexible approach are discussed. In Section 4, multi-domain and multi-material topology optimization of support and multi-layer structure under an external load and self-weight is performed, and obtained results are presented. The discussed approach is adapted also to strengthening and retrofitting selected structures in Section 5, where the numerical calculations are performed both for single- and multiple-load cases. The paper ends with concluding remarks.

\section{Sub-Domain Based Multi-Material Topology Optimization}

Within a design domain, the problem of structural topology optimization is to find the distribution of material giving the minimal value of the compliance of the structure $c$ (Equation (1)). The design domain is discretized by finite elements. The available material volume fraction $\kappa$ is defined and treated as a constraint in the optimization process (Equation (2)).

$$
\begin{array}{cl}
\text { minimize } & c(\mathbf{d})=\mathbf{U}^{\mathrm{T}} \mathbf{K U}=\sum_{i=1}^{N} d_{i}^{p} \mathbf{u}_{i}^{T} \mathbf{k}_{i} \mathbf{u}_{i} \\
& \text { subject to } \quad V=\kappa V_{0} \\
& \mathbf{K U}=\mathbf{F} \\
& 0<d_{\text {min }} \leq d_{i} \leq 1 .
\end{array}
$$

In Equations (1)-(4), $\mathbf{U}$ and $\mathbf{F}$ are the global displacement and force vectors, $\mathbf{K}$ is the global stiffness matrix, $\mathbf{u}_{i}$ and $\mathbf{k}_{i}$ are the element displacement vector and stiffness matrix, respectively, and $N$ is the number of elements, while $d_{i}$ is a design variable that represents a relative density of the material assigned to each element. The constraints are imposed on the values of design variables, and $d_{\min }$ is a non-zero minimum relative density introduced to avoid singularity.

As the material representation, the SIMP (Solid Isotropic Material with Penalization) power law approach [42] is adapted. The elastic modulus $E_{i}$ of each finite element is modeled as a function of the design variable $d_{i}$. In Equation (5), $p$ (typically $p=3$ ) penalizes intermediate densities and drives the design of black-and-white structures. $E_{0}$ and $\rho_{0}$ are the elastic modulus and density of a solid material, respectively.

$$
E_{i}=d_{i}^{p} E_{0}, \quad \rho_{i}=d_{i} \rho_{0} .
$$

When dealing with the self-weight loading, the modification and extension of the standard SIMP method is necessary (see [43]), such that the solid material density $\rho_{0}$ of each element is defined according to Equation (6):

$$
\rho_{i}=d_{i}^{p} \rho_{0} .
$$

It is proposed to extend the conventional concept of topology optimization by introducing the idea of multi-domain and multi-material topology optimization. A typical approach regards redistribution of one or several materials within a whole design domain, but this paper proposes a different approach. The design domain is divided into subregions for which different types of material are defined, and through this procedure, the multi-material structure is created. Following the preliminarily findings of [44], the aim of the present research is to find optimal topologies, under the restriction that redistribution of material can be performed only within sub-domains selected for employed materials. What is very important, in terms of practical applications, is that it is possible to impose separate constraints on volume fractions of each defined material. This approach produces different results when compared to the traditional problem, which is the redistribution of one or few materials within the whole design domain. Allowing for implementation of many materials during the topology optimization process may open new possibilities for improving existing solutions. In addition, including the self-weight loading makes the considered design problems more practical and realistic, although more complicated 
in terms of computation. The nature of this type of loading, namely, design-dependent loading, is that the location, direction and magnitude of the loads depend on the current shape of the structure in the current optimization step. Topology optimization of structures under design-dependent loads is rather rarely considered in the literature. This approach requires modifying known and widely recognized approaches due to the potential occurrence of such issues as a non-monotonous behavior of the compliance, parasitic effect or unconstrained character of the optimum, which means that the volume constraint can be inactive for optimal topology.

\section{Cellular Automata Rules for Topology Optimization}

The effectiveness of the topology optimization process is determined by selecting a proper method of numerical optimization. Heuristic optimization techniques are gaining popularity among researchers—see, e.g., [45,46]—-because they are easy for numerical implementation, do not require gradient information, and one can easily combine this type of algorithm with any finite element structural analysis code. This practical aspect of engineering implementation of topology optimization techniques seems to be an important issue for contemporary design.

This paper utilizes an efficient heuristic approach based on the concept of Cellular Automata (CA). The main idea of CA is to replace a complex problem with a sequence of simple decision-making based on local information and local interaction between cells. The implementation of Cellular Automata requires decomposition of the design domain into a usually, but not always, e.g., [47], uniform lattice of cells that are equivalent to finite elements while performing analysis and topology optimization. It is assumed that the interaction between cells takes place only within the neighboring cells and is governed by local rules. The rules are identical for all cells and are applied simultaneously to each of them. Updating the state of cells can be performed based on already updated values found for cell neighbors (the Gauss-Seidel update scheme) or based on the states of the surrounding cells determined in the previous iteration (the Jacobi update scheme).

In this paper, a heuristic local update rule is proposed utilizing the Jacobi update scheme (see Equation (7)), where $t$ is the current iteration number:

$$
\begin{gathered}
d_{i}^{(t+1)}=d_{i}^{(t)}+\Delta d_{i}^{(t)}, \\
\Delta d_{i}^{(t)}=\frac{1}{M+1}\left[\sum_{k=1}^{M} \alpha_{i k}+\alpha_{i}\right] m .
\end{gathered}
$$

In Equation (8), $m$ denotes move limit (e.g., $m=0.2$ ). The coefficients $\alpha_{i}$ for central cell $i$ and $\alpha_{i k}$ for $M$ neighboring cells are calculated based on the following rules [48]:

$$
\alpha_{i}=\left\{\begin{array}{c}
-C_{\alpha} \text { if } c_{i} \leq c^{*} \\
C_{\alpha} \text { if } c_{i}>c^{*}
\end{array} ; \quad \alpha_{i k}=\left\{\begin{array}{c}
-C_{\alpha} \text { if } c_{i k} \leq c^{*} \\
C_{\alpha} \text { if } c_{i k}>c^{*}
\end{array},\right.\right.
$$

where $c_{i}$ (Equation (9)) is the value of the compliance of a central cell, and $c_{i k}$ stands for the compliance of neighboring ones. The quantity $C_{\alpha}$ is a user-specified parameter [48].

In this paper, a modification of these rules is proposed. To make local rules more flexible, instead of one threshold value $c^{*}$, two values $c_{1}{ }^{*}$ and $c_{2}{ }^{*}$ are introduced.

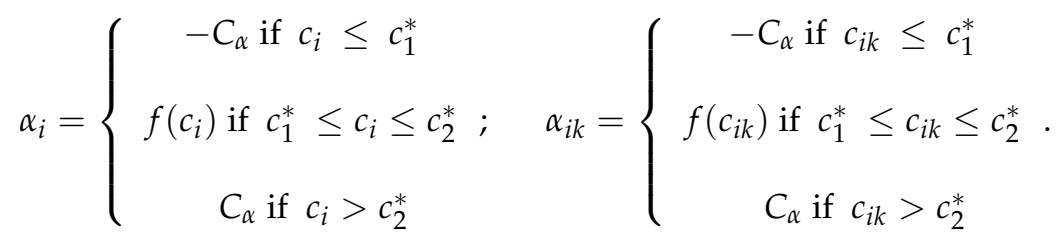


At the same time, the linear function in Equation (10) is built to fulfill the conditions $f\left(c_{1}^{*}\right)=-C_{\alpha}$ and $f\left(c_{2}^{*}\right)=C_{\alpha}$; thus

$$
f(c)=2 C_{\alpha} \frac{c}{c_{2}^{*}-c_{1}^{*}}-C_{\alpha} \frac{c_{2}^{*}+c_{1}^{*}}{c_{2}^{*}-c_{1}^{*}} .
$$

The values of the function $f(c)$ (Equation (11)) refer to all compliances from the interval $\left[c_{1}^{*}, c_{2}^{*}\right]$. The width of the interval can be modified during the optimization process. This gives the function $f(c)$ more flexibility, allowing for the choice between linear functions of different slopes, and the step $\left(-C_{\alpha}, C_{\alpha}\right)$ one if $c_{2}{ }^{*}-c_{1}{ }^{*}$ tends to zero. One can, for example, start with a wide interval, decreasing it as the generation of topologies proceeds, or the opposite: start with one threshold value $c_{1}{ }^{*}=c_{2}{ }^{*}=c^{*}$ and then increase the interval around $c^{*}$. Implementing the adaptive technique by decreasing the interval $\left[c_{1}{ }^{*}, c_{2}{ }^{*}\right]$ can, for example, speed up the process of the so-called grey elements elimination at the final stage of topology generation.

The numerical algorithm was built in order to implement the design rule proposed above. As for the optimization procedure, the sequential approach was adapted, meaning that for each iteration, the structural analysis performed for the optimized element was followed by a local updating process. Simultaneously, a global volume constraint can be applied for a specified volume fraction. The volume constraint is implemented in each iteration when local update rules are applied to all elements. In practice, the design variables multiplier is introduced, and then its value is sought to fulfill the volume constraint. As a result, the generated topologies preserve a specified volume fraction of a solid material during the optimization process. In this paper, the Finite Element Analysis tool (ANSYS) stands for the structural analysis module.

In the present study, the assumed change of the objective function value for subsequent iterations was implemented as the stopping criterion, but in general, the criterion can also be defined as performing a selected number of iterations.

It is worth noticing that the total volume constraint can be inactive while considering topology optimization including self-weight loading. The proper choice of $c_{1}{ }^{*}, c_{2}{ }^{*}$ and $C_{\alpha}$ can eliminate this problem.

\section{Multi-Domain and Multi-Material Topology Optimization}

\subsection{Example 1-Support Structure}

4.1.1. Topology Optimization of Uni-Material Structure under External Load

As the first example, a plane elastic support structure bolted on two brackets presented in Figure 1 was chosen, assuming the symmetry of the structure. The structure is discretized with a regular lattice of tetragonal cells. The number of cells equals 8005. Firstly, the topology optimization using one material $\mathrm{M}_{1}$ with the Young modulus equal to $\mathrm{E}_{1}=2 \times 10^{11} \mathrm{~Pa}$, the Poisson ratio $v_{1}=0.3$ and density $\rho_{1}=8000 \mathrm{~kg} / \mathrm{m}^{3}$ was performed. The volume fraction equal to 0.5 was implemented. The volume fraction was constant during the optimization process, and it is checked after each iteration (applies to all the examples considered in the paper). Due to symmetry, one half of the structure was considered. 


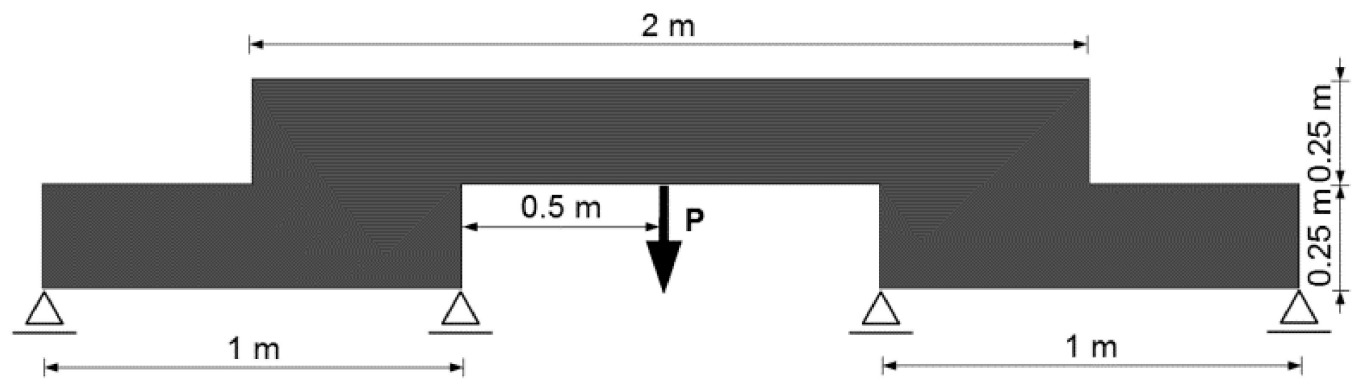

Figure 1. The initial structure with applied loads and supports, material $\mathrm{M}_{1}$.

For the first calculation, a concentrated force equal to $\mathrm{P}_{1}=1000 \mathrm{~N}$ was applied. The final topology with the resultant compliance equal to $4.866 \times 10^{-6} \mathrm{Nm}$ is presented in Figure 2, while the compliance of the initial structure with uniformly distributed material is equal to $8.482 \times 10^{-6} \mathrm{Nm}$. At the same time, the maximal displacement of $0.243 \times 10^{-7} \mathrm{~m}$ is reached for the final distribution of the available material, while for the initial structure the maximal displacement equals $0.424 \times 10^{-7} \mathrm{~m}$. It is important to note that the final topology for this case of loading does not depend on the value of applied loading.

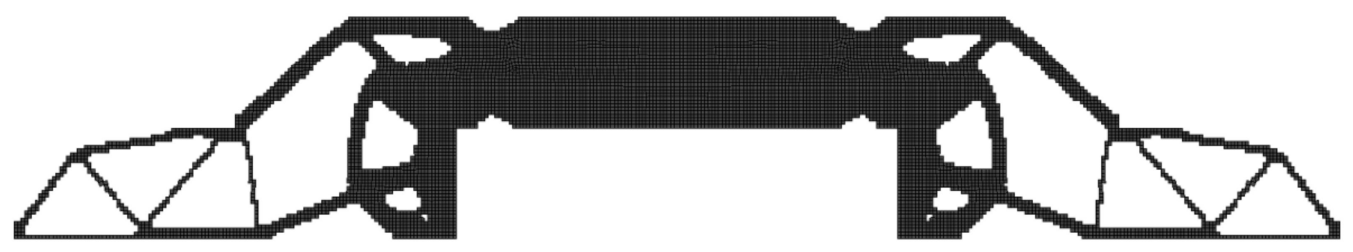

Figure 2. The final topology for the structure loaded with the concentrated force $P_{1}=1000 \mathrm{~N}$, material $\mathrm{M}_{1}$.

To illustrate the effectiveness of the proposed approach, the computing time for the examples discussed in the paper was examined. As a metric of the algorithm runtime, a clock-time was used. Each iteration consisted of two stages: FEM analysis and design variable update. The time of the update step had a minor influence on the resultant time of the calculation process (it took less than 1 or $2 \mathrm{~s}$, even for a large number of elements), while the structural analysis time depended highly on the mesh resolution (the number of elements used for the discretization of the structure). For all 2D examples considered in the paper, the 4-node finite element was used, and for 3D examples, the 8-node element. ANSYS Mechanical APDL was used as the analysis tool with AMD Phenom(tm) II X4 955 $3.20 \mathrm{GHz}$ processor and $8 \mathrm{~GB}$ of RAM (64-bit architecture). For the example presented in this section (8005 elements), 30 iterations were needed to reach a convergence, which took about $3 \mathrm{~min}$ (one half of the structure was investigated due to the symmetry). The iteration history showing the convergence of the objective function is provided in Figure 3.

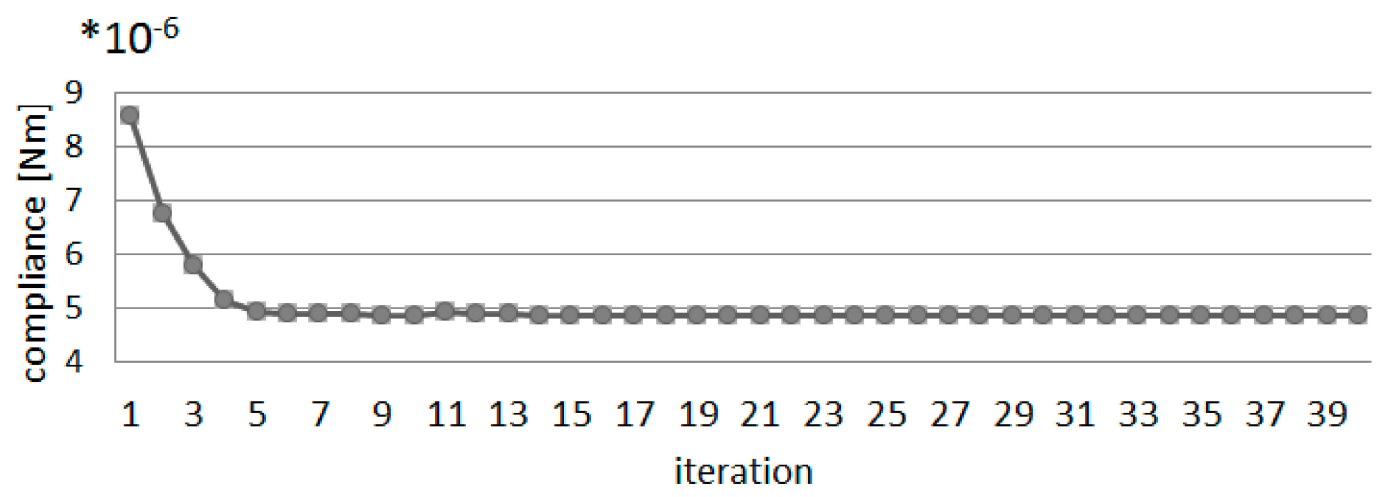

Figure 3. The iteration history. 
In order to broaden the discussion regarding this example, the problem has been reformulated by replacing the volume constraint by the mass constraint. In what follows, the mass constraint $\mu=0.5$ has been implemented for the same geometry, material data and boundary conditions. As was expected for uni-material problem, the final values of compliance and maximal displacement are the same, since the volume and mass constraints are in this case equivalent.

The final topology, with resultant compliance and maximal displacement equal to $4.866 \times 10^{-6} \mathrm{Nm}$ and $0.243 \times 10^{-7} \mathrm{~m}$, respectively, is presented in Figure 4, whereas Figure 5 shows iterations history. It can be noted that less than 30 iterations were needed to reach a convergence.

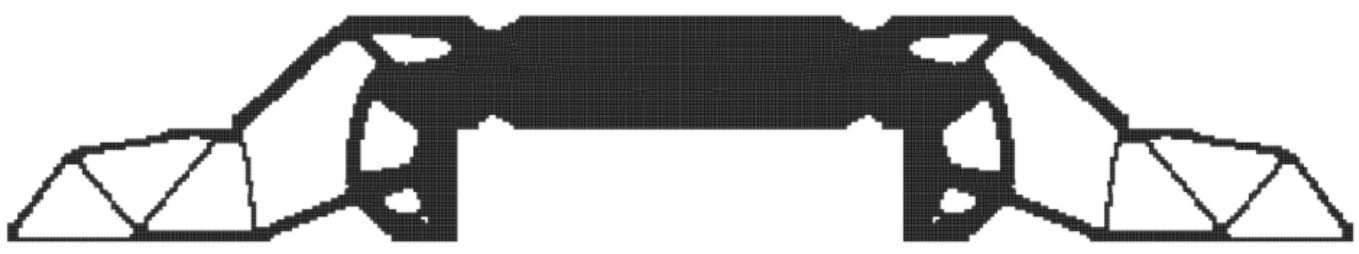

Figure 4. The final topology of the considered structure under mass constraint.

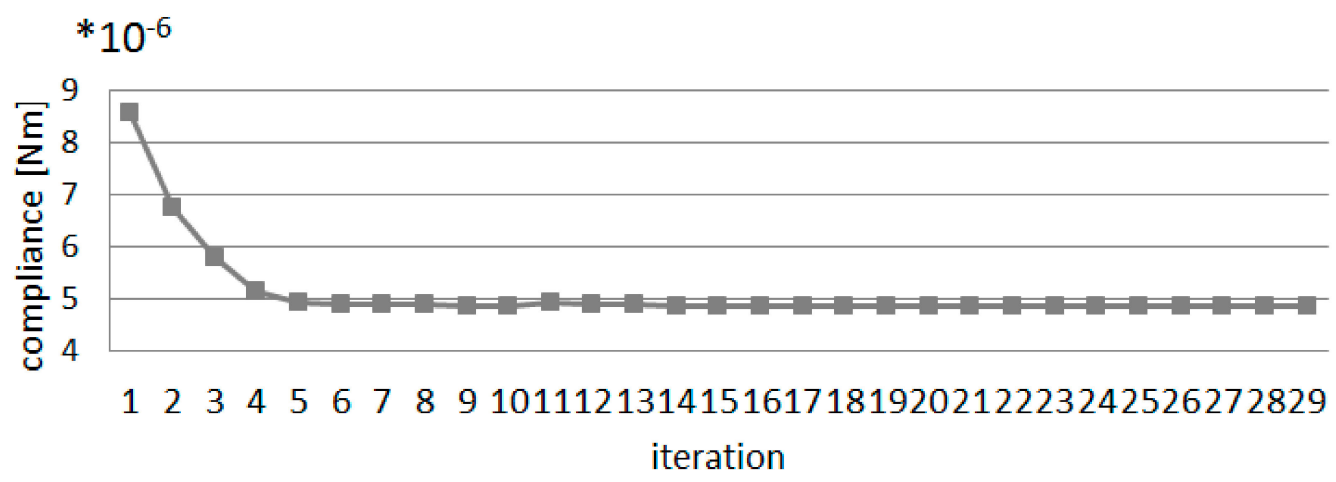

Figure 5. The iterations history.

\subsubsection{Topology Optimization of Multi-Material Structure under External Load}

For the next example, the two materials $\mathrm{M}_{1}$ and $\mathrm{M}_{2}$ with different material data were applied as shown in Figure 6.

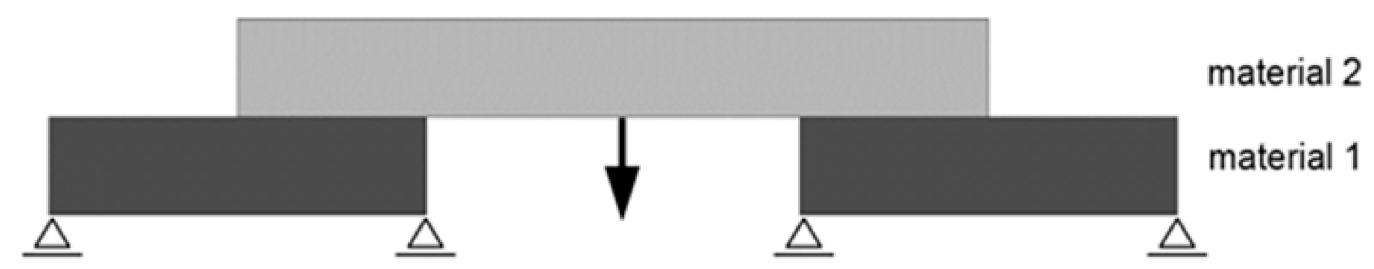

Figure 6. The initial multi-material structure with applied loads and supports, materials $\mathrm{M}_{1}$ and $\mathrm{M}_{2}$.

Both materials are linear elastic and isotropic. Material $1\left(\mathrm{M}_{1}-\right.$ drawn in Figure 6 in dark grey color) is characterized by a Young modulus equal to $\mathrm{E}_{1}=2 \times 10^{11} \mathrm{~Pa}$, the Poisson ratio $v_{1}=0.3$ and density $\rho_{1}=8000 \mathrm{~kg} / \mathrm{m}^{3}$; the second one-material $2\left(\mathrm{M}_{2}\right.$-drawn in Figure 6 in light grey color) is characterized by a Young modulus equal to $E_{2}=2 \times 10^{10} \mathrm{~Pa}$, the Poisson ratio $v_{2}=0.3$ and density $\rho_{2}=2000 \mathrm{~kg} / \mathrm{m}^{3}$. The ratios of the Young modulus and density values calculated for material $\mathrm{M}_{1}$ and material $\mathrm{M}_{2}$ are approximately the same as the ratios of these quantities for steel and concrete (compression). The same calculations as for the uni-material structure were performed, i.e., for a structure loaded only with a concentrated force equal to $1000 \mathrm{~N}$. The final topology gained for this case is presented 
in Figure 7. The presented results show that multi-material topology optimization has to be treated as a separate/different approach, since it can give a new layout of material distribution for the optimized structure.

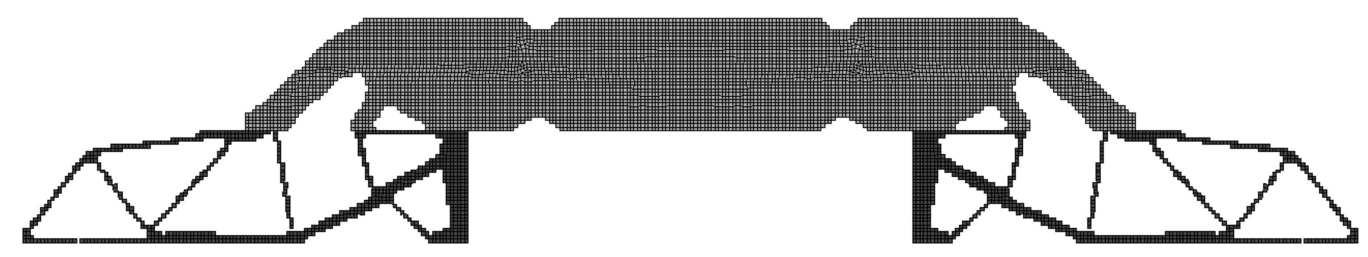

Figure 7. The final topology for the structure loaded with the concentrated force $P_{1}=1000 \mathrm{~N}$, materials $\mathrm{M}_{1}$ and $\mathrm{M}_{2}$.

The final compliance of the optimized structure equals $0.310 \times 10^{-2} \mathrm{Nm}$, while the compliance of the initial structure with uniformly distributed material is equal to $0.539 \times 10^{-2} \mathrm{Nm}$. At the same time, the maximal displacement of $0.176 \times 10^{-5} \mathrm{~m}$ is reached for the final distribution of the available material, while the maximal displacement of the initial structure is equal to $0.269 \times 10^{-5} \mathrm{~m}$.

For the example presented in Figure 7 (8005 elements), 33 iterations were needed to reach a convergence, which takes about $3 \mathrm{~min}$ (half of the structure was investigated due to the symmetry). The iteration history showing the convergence to the final solution is provided in Figure 8.

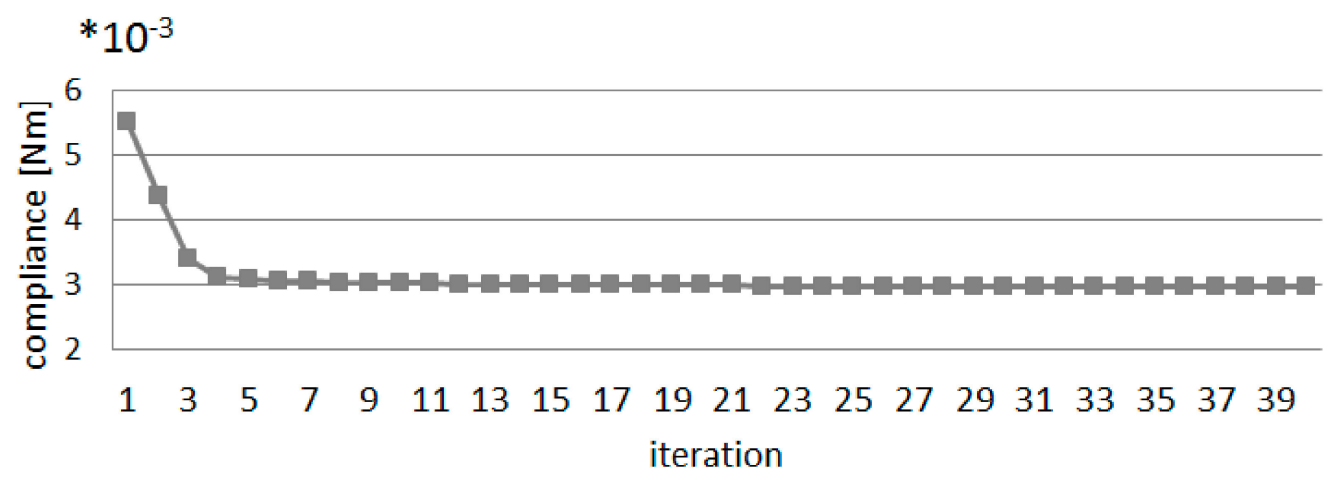

Figure 8. The iteration history.

The presented example was remodeled into a three-dimensional structure by adding a third dimension-the thickness equal to $0.25 \mathrm{~m}$. A quarter of the structure was investigated due to symmetry. All materials data as well as the boundary conditions are the same as for the 2D example presented in Figure 6. The same calculations were performed to illustrate the effectiveness of the algorithm. The value of the final compliance for the optimized structure equals $0.155 \mathrm{Nm}(0.303 \mathrm{Nm}$ for the initial structure), and the final maximal displacement equals $0.386 \times 10^{-4} \mathrm{~m}\left(0.758 \times 10^{-4} \mathrm{~m}\right.$ for the initial structure $)$. The final topology is presented in Figure 9.

For the example presented above (20,808 elements), 37 iterations were needed to reach a convergence, which takes about 12 min (a quarter of the structure was investigated due to the symmetry). The iteration history showing the convergence to the final solution is provided in Figure 10. 


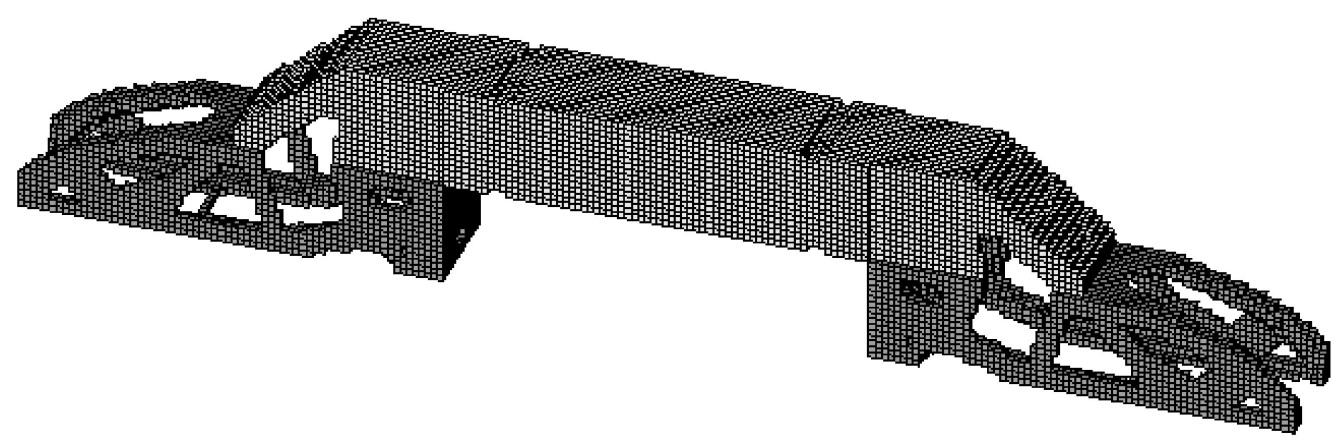

Figure 9. The final topology for the 3D structure.

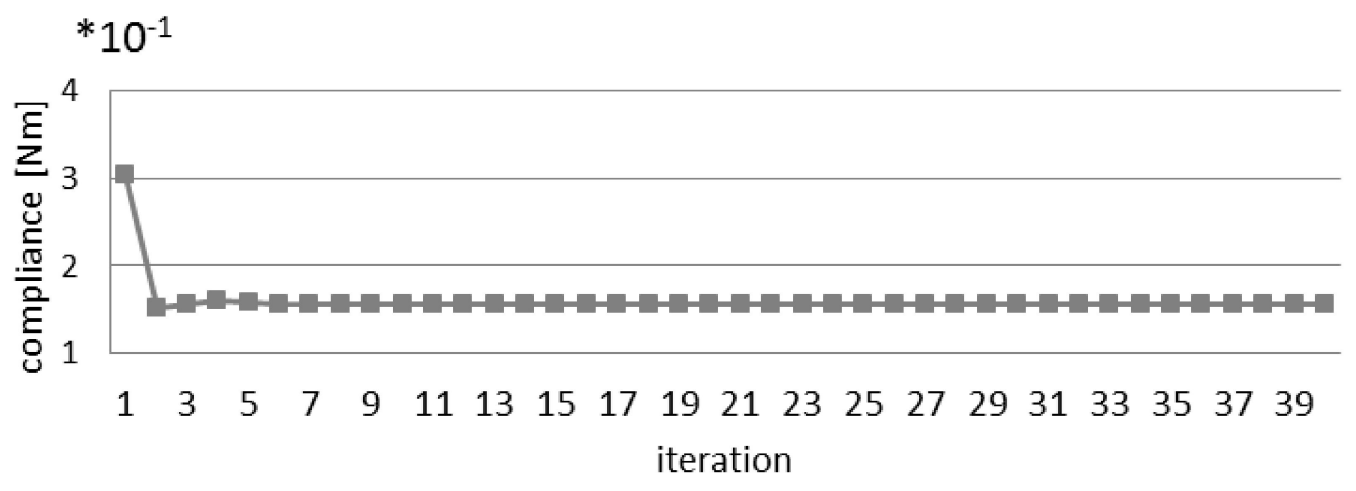

Figure 10. The iteration history.

As for the previous example, the considerations regarding the multi-material 2D structure have been extended by replacing the volume constraint with the mass constraint. In what follows, the mass constraint $\mu=0.5$ was implemented for the same geometry, material data and boundary conditions. This time, since the multi-material structure is investigated, the constraint replacement influences the final results. The compliance of the optimized structure equals $0.276 \times 10^{-2} \mathrm{Nm}$, while the maximal displacement $0.138 \times 10^{-5} \mathrm{~m}$. The final topology is presented in Figure 11. The iteration history showing the convergence to the final solution is provided in Figure 12 (30 iterations were needed to get the solution). It is worth underlining that the reformulation of the problem has no influence on the convergence of the calculations.

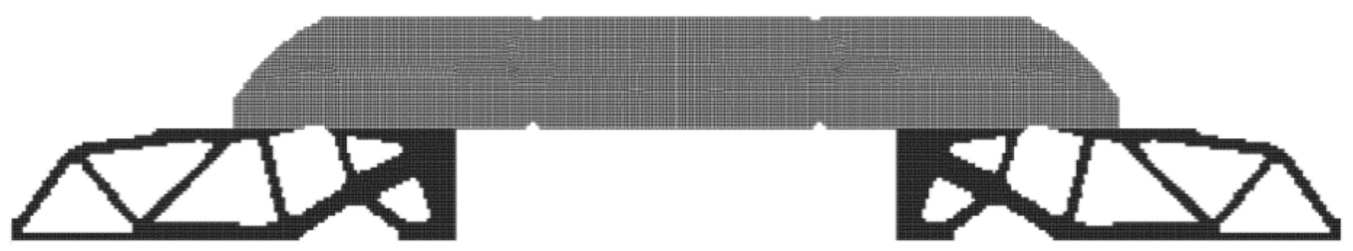

Figure 11. The final topology of the considered structure under mass constraint.

If properly interpreted, the topology optimization results may be an inspiration for architects and engineers at an early design stage. One can see that for generated topologies, small holes or slender rods can occur. Those elements can be difficult to manufacture, and in the case of slender rods, they can be exposed to the loss of stability. To prevent the problems mentioned, either manufacturing constraints can be applied or those elements need to be modified or removed in the final design steps. 


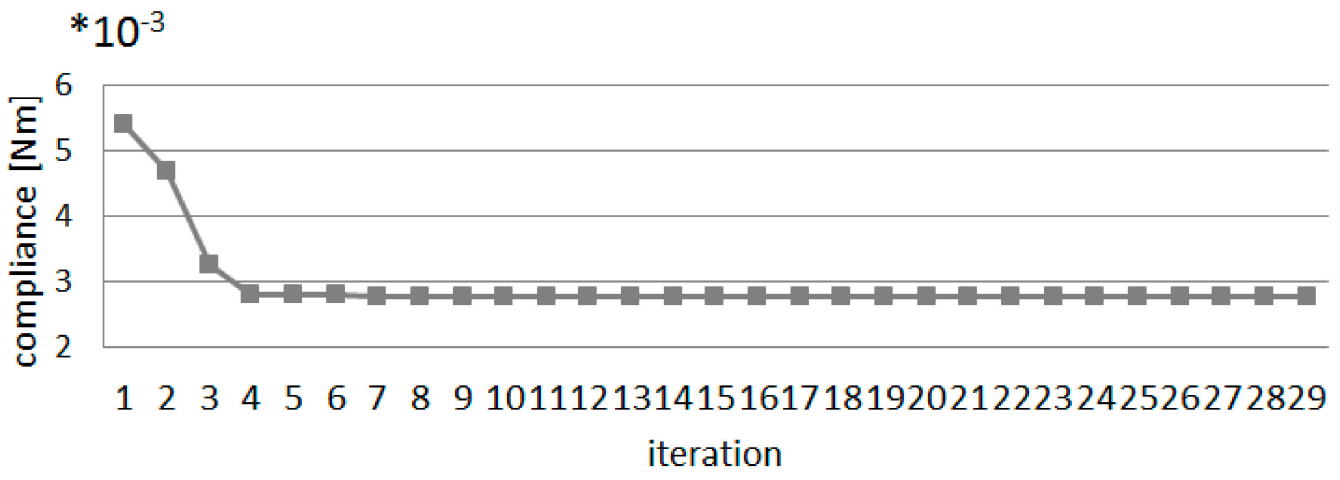

Figure 12. The iteration history.

4.1.3. Topology Optimization of Multi-Material Structure under External Load and the Self-Weight

Next, the optimization process was performed for the same structure, but self-weight loading was additionally included, with the gravity acceleration equal to $9.81 \mathrm{~m} / \mathrm{s}^{2}$. The implementation of self-weight loading has a significant influence on the final results of the topology optimization process, which is very important, especially when dealing with the optimization of massive engineering structures, for example, bridges or carrying systems of tall buildings. Topology optimization of structures under design-dependent loads cannot be treated as an extension of standard formulation of topology optimization under fixed loads and therefore requires modifications of known and well-recognized approaches and algorithms. The presented study shows that the proposed local rule can be effective also for the more complicated problems like design-dependent loads. The final topology is shown in Figure 13. The value of compliance for the final topology equals $2.531 \times 10^{-2} \mathrm{Nm}$, and the final displacement equals $0.336 \times 10^{-5} \mathrm{~m}$, while for the initial structure they are $4.333 \times 10^{-2} \mathrm{Nm}$ and $0.454 \times 10^{-5} \mathrm{~m}$, respectively.

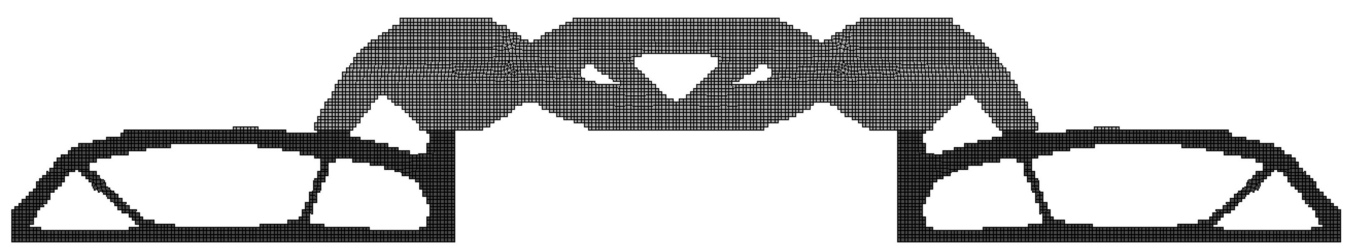

Figure 13. The final topology for the structure loaded with the concentrated force $P_{1}=1000 \mathrm{~N}$ and self-weight, materials $M_{1}$ and $\mathrm{M}_{2}$.

For the above example (8005 elements), 30 iterations were needed to reach a convergence, which took about 3 min (one half of the structure was investigated due to the symmetry). The iteration history showing the convergence to the final solution is provided in Figure 14.

The calculations were repeated for the corresponding three-dimensional structure (thickness of $0.25 \mathrm{~m}$ ), as was done in the previous section, and the final results are presented in Figure 15. The value of final compliance for the optimized structure equals $0.204 \mathrm{Nm}(0.399 \mathrm{Nm}$ for the initial structure), and the final maximal displacement equals $0.431 \times 10^{-4} \mathrm{~m}\left(0.833 \times 10^{-4} \mathrm{~m}\right.$ for the initial structure $)$. 


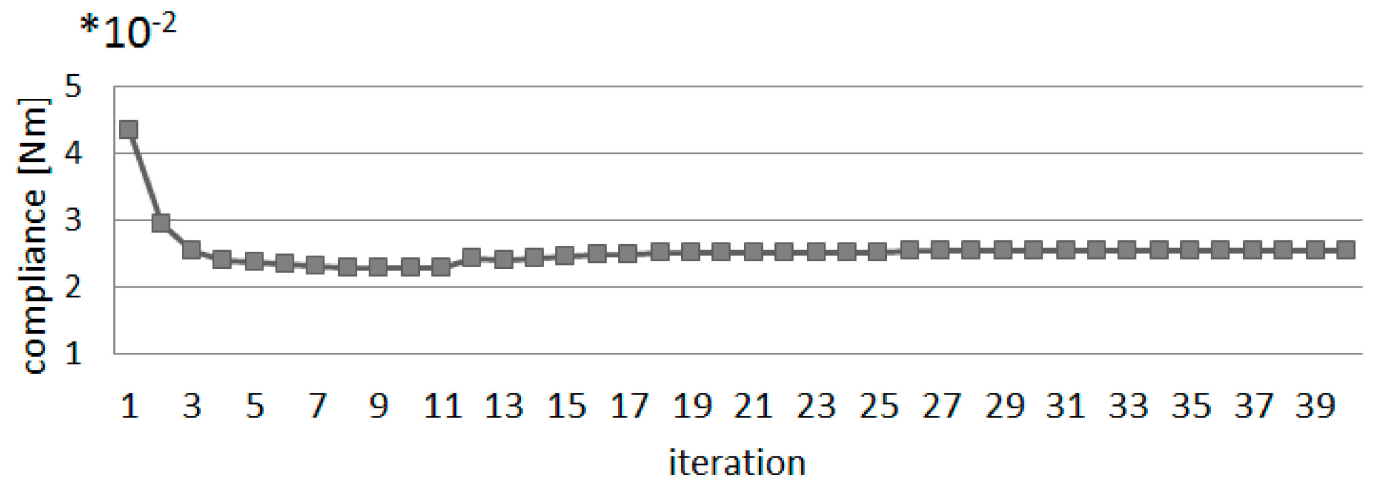

Figure 14. The iteration history.

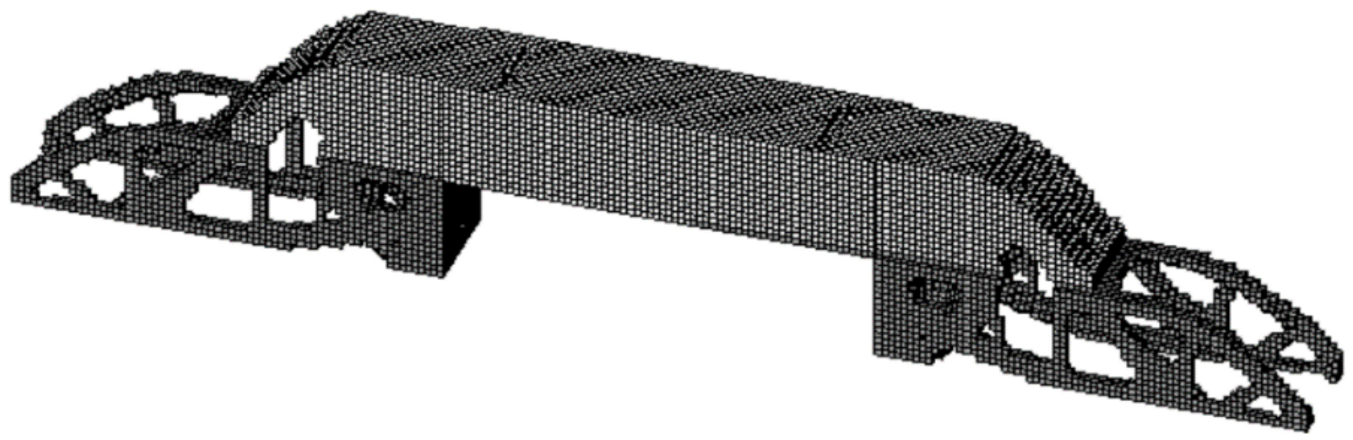

Figure 15. The final topology for the 3D structure including self-weight.

For this example (20,808 elements), 35 iterations were needed to reach a convergence, which took less than $12 \mathrm{~min}$ (onequarter of the structure was investigated due to the symmetry). The iteration history showing the convergence to the final solution is provided in Figure 16.

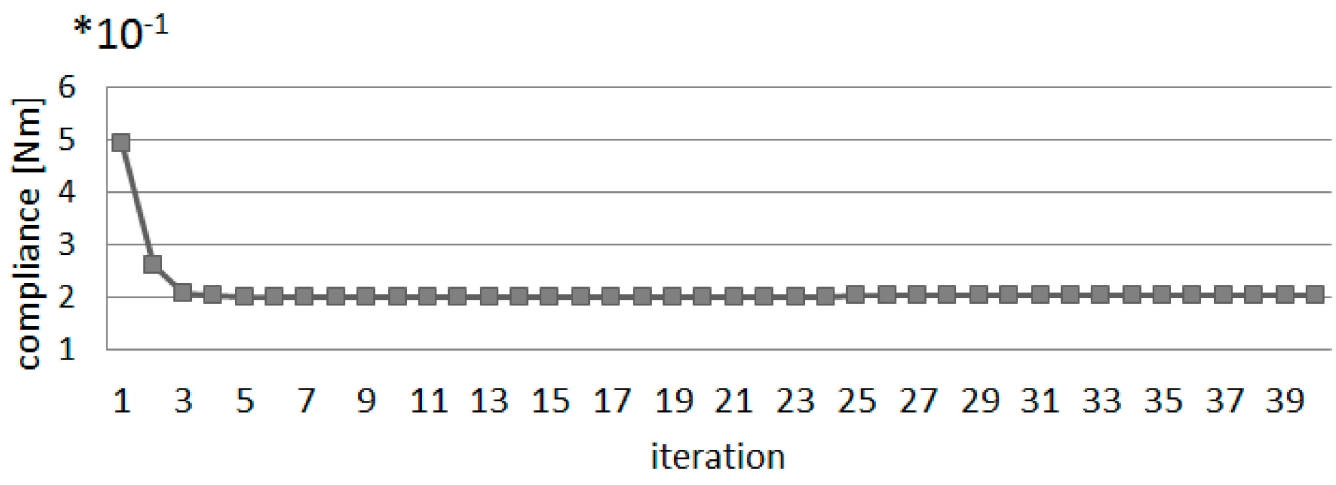

Figure 16. The iteration history.

As for the previous example, the considerations regarding the multi-material 2D structure were extended by replacing the volume constraint with the mass constraint. In what follows, the mass constraint $\mu=0.5$ was implemented for the same geometry, material data and boundary conditions. This time, since the multi-material structure was investigated, the constraint replacement influences the final results. The compliance of the optimized structure equals $0.276 \times 10^{-2} \mathrm{Nm}$, while the maximal displacement $0.138 \times 10^{-5} \mathrm{~m}$. The final topology is presented in Figure 17. The iteration history showing the convergence to the final solution is provided in Figure 18 (30 iterations were needed to get the solution). It is worth underlining that the reformulation of the problem has no influence on the convergence of the calculations. 


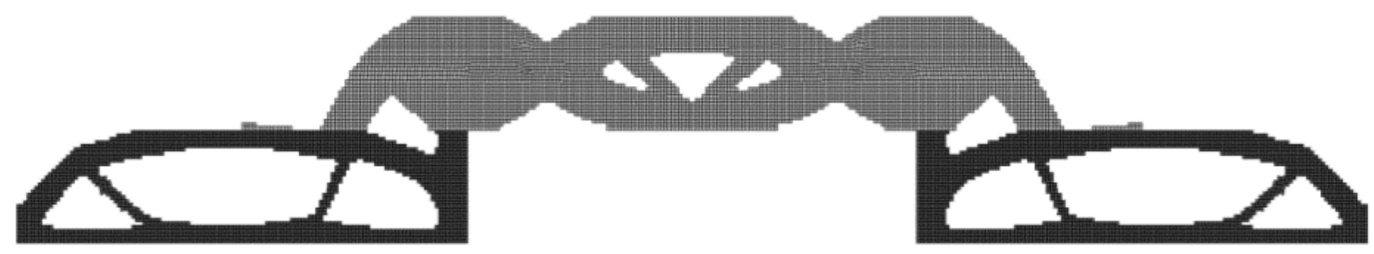

Figure 17. The final topology of the considered structure under mass constraint.

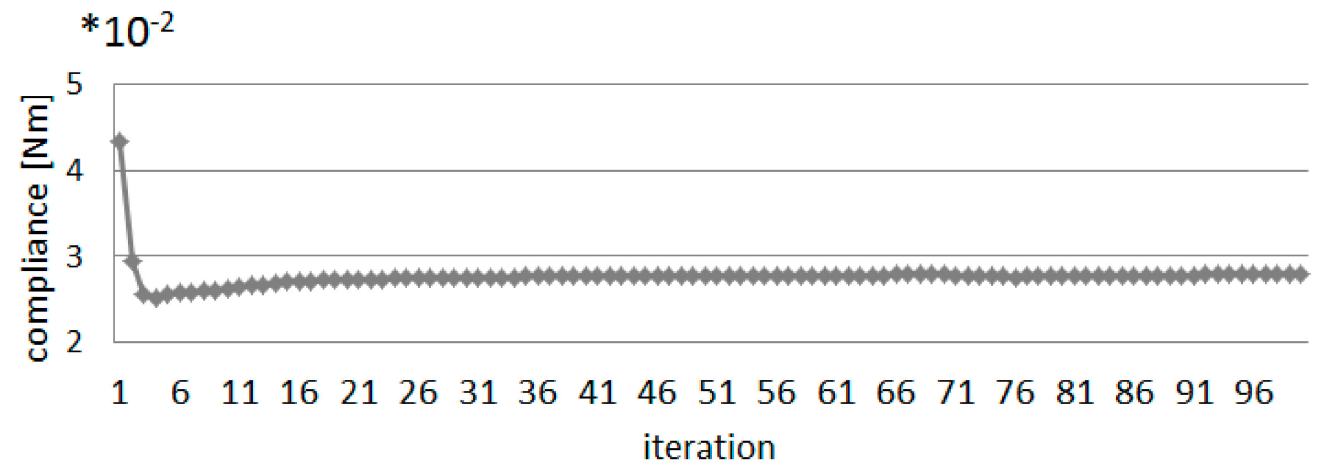

Figure 18. The iteration history.

\subsection{Example 2-Multi-Layer Structure}

A multi-layer structure presented in Figure 19 was chosen as the next example. This structure can model a massive engineering structure for which the consideration of selfweight loading is required. In addition, the application of multi-material solutions for this type of structure can be found in architectural and structural engineering practice. In this case, the threshold values $c_{1}{ }^{*}=c_{2}{ }^{*}$ are selected and calculated based on the average compliance of the structure.

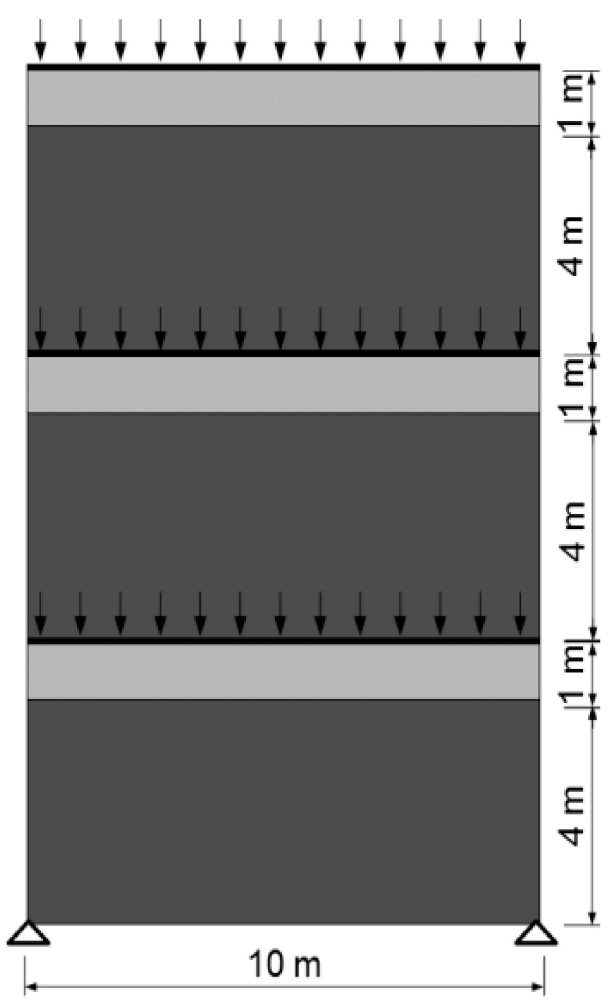

Figure 19. The multi-layer structure with applied loads and supports, material $M_{1}$ and $M_{2}$. 
The multi-layer structure is built of two materials. Both materials are linear, elastic and isotropic. Material $1\left(\mathrm{M}_{1}\right.$ drawn in Figure 19 in dark grey color) is characterized by the Young modulus equal to $E_{1}=2.1 \times 10^{5} \mathrm{MPa}$, the Poisson ratio $v_{1}=0.3$ and density $\rho_{1}=7860 \mathrm{~kg} / \mathrm{m}^{3}$; whereas material $2\left(\mathrm{M}_{2}\right.$ drawn in Figure 19 in light grey color $)$ is characterized by the Young modulus equal to $\mathrm{E}_{2}=2.7 \times 10^{4} \mathrm{MPa}$, Poisson ratio $v_{2}=0.2$ and density $\rho_{2}=2500 \mathrm{~kg} / \mathrm{m}^{3}$. The black regions simulating girders are excluded from the design process. The structure is loaded by the external pressure equal to $210^{4} \mathrm{~N} / \mathrm{m}$ acting on each girder as is shown in Figure 19.

4.2.1. Topology Optimization of Multi-Material Multi-Layer Structure under External Load and Self-Weight

The topology optimization of the structure under external was performed, and the results are presented in Figure 20a. For the final topology, the values of compliance and maximal displacement are $11.164 \mathrm{Nm}$ and $0.242 \times 10^{-4} \mathrm{~m}$, while for the initial structure, they are equal to $17.791 \mathrm{Nm}$ and $0.326 \times 10^{-4} \mathrm{~m}$, respectively.

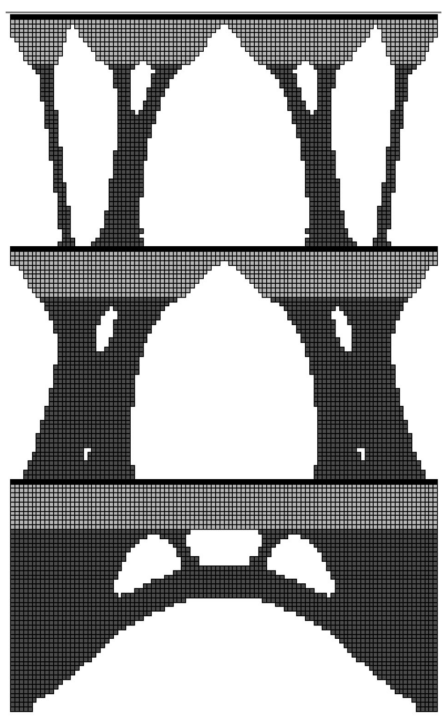

(a)

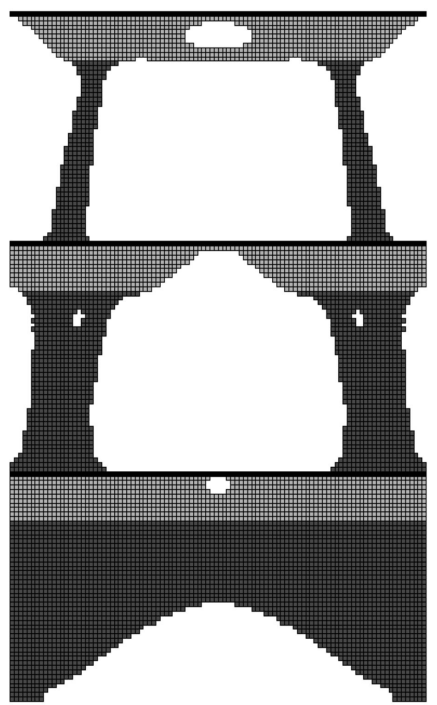

(b)

Figure 20. (a) The final topology for the structure loaded by the external pressure, material $\mathrm{M}_{1}$ and $\mathrm{M}_{2}$. (b) The final topology for the structure loaded by the external pressure and self-weight, material $\mathrm{M}_{1}$ and $\mathrm{M}_{2}$.

Next, the generation of optimal topology for the multi-layer structure was performed, but this time with the self-weight loading included. The final topology is shown in Figure 20b. The value of compliance for the final topology equals $544.38 \mathrm{Nm}$, whereas the maximal displacement is equal to $0.191 \times 10^{-3} \mathrm{~m}$. For the initial structure, the respective values are $1379.33 \mathrm{Nm}$ and $0.268 \times 10^{-3} \mathrm{~m}$.

For this example (15,300 elements), 30 iterations were needed to reach a convergence, which took about $4 \mathrm{~min}$. Figure 21 shows the iteration history for the convergence to the final solution without self-weight loading (topology presented in Figure 20a). Figure 22 shows the solution with self-weight loading (topology presented in Figure 20b). 


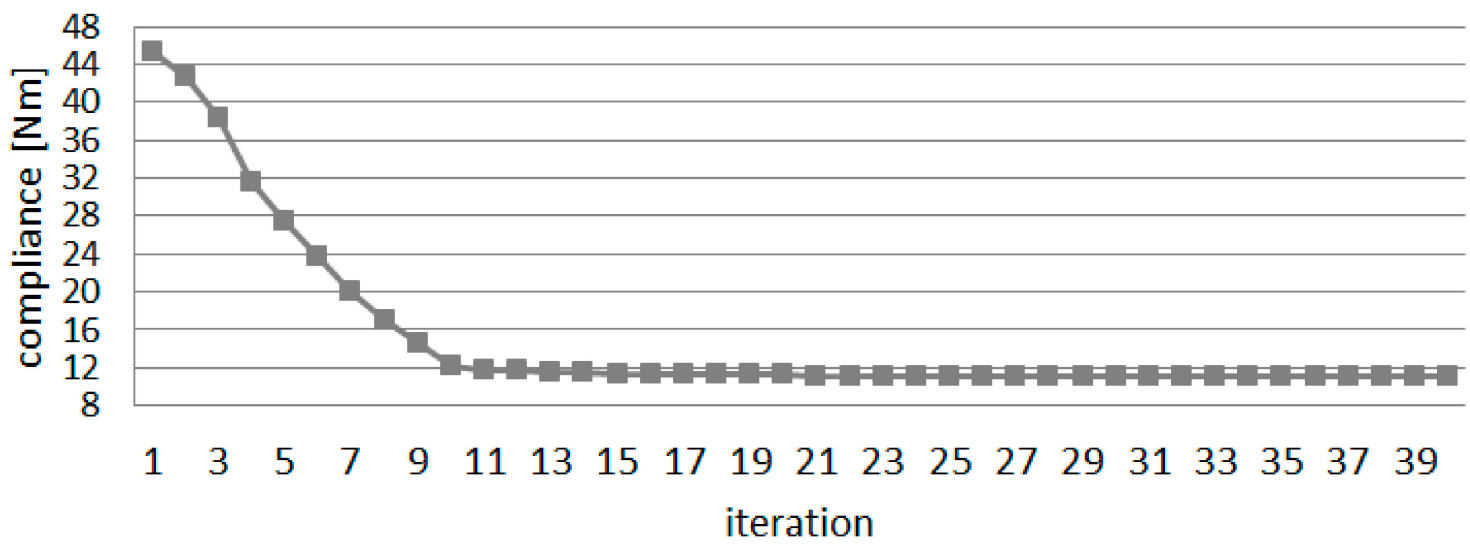

Figure 21. The iteration history for a structure loaded only by external forces.

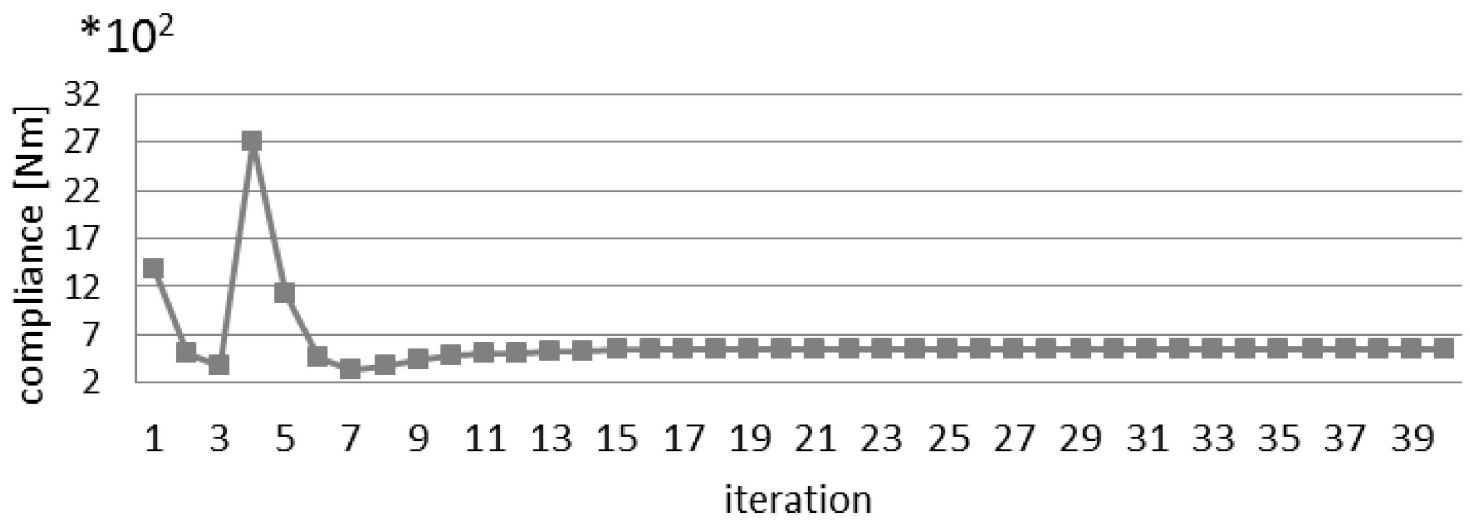

Figure 22. The iteration history for a structure loaded by external forces and self-weight.

4.2.2. Topology Optimization of Multi-Material Multi-Layer Structure under External Load and Self-Weight-Design of the Reinforcement

The present consideration regards the implementation of the sub-domain-oriented topology optimization to the special case of the design domain selection. In what follows, only one part of the multi-layer structure, selected in three different ways, is considered to be the design domain. As previously, the external pressure and self-weight loading were applied. The final topologies obtained for the three cases under consideration are presented in Figure 23. One can observe that the location of the selected design domain significantly influences not only the generated topology but also the final value of compliance. The results of calculations are $2025.02 \mathrm{Nm}$ for the structure on the left, $1756.25 \mathrm{Nm}$ for the middle one and $1501.25 \mathrm{Nm}$ for the one on the right. The above-mentioned approach allows for a sample modification of supports of existing structures with a view to obtain the minimal compliance of the reinforcement. 


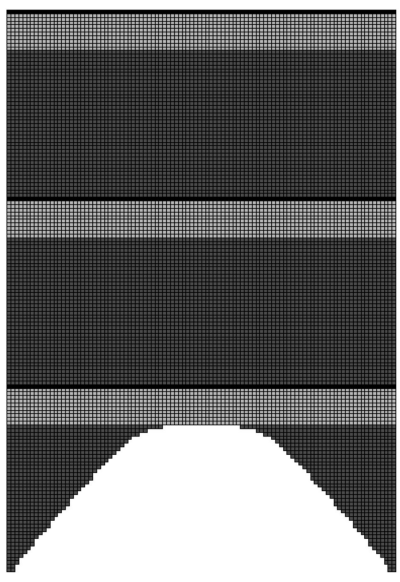

(a)

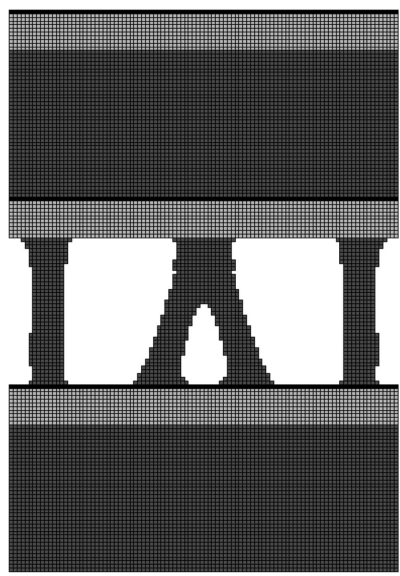

(b)

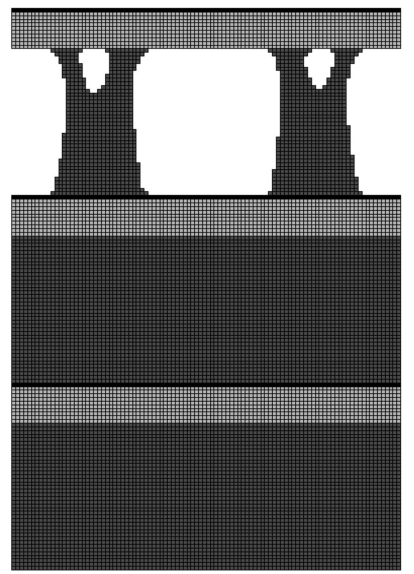

(c)

Figure 23. Final topologies for sub-domain-oriented multi-material topology optimization.

\section{Topology Optimization Techniques Adapted to Strengthening and Retrofitting of Civil Structures}

In the case of cultural and architectural heritage, strengthening weakened material and retrofitting structural damage can be a concern for historians and architects, but also for engineers. The implementation of innovations in engineering and science seems to be an attractive alternative to conventional, well-known ideas. Following this line of reasoning, this paper proposes a concept for optimal designing of a restoration process, which allows reducing the mass of strengthening elements, including one or more applied materials.

\subsection{Strengthening of Structures Suffering from the Effects of Material Degradation}

An attempt to build a simple but effective technique for design strengthening for cultural heritage monuments and historical buildings suffering from the effects of material degradation is made in this section. It is proposed to treat the restoration process as a topology-optimization task, in which the strengthening with a low volume of material and maximal stiffness are sought for.

As an example of strengthening civil structures suffering from the effects of material degradation using multi-domain and multi-material oriented topology optimization, the bridge structure presented in Figure 24 was selected. The bridge is loaded by a uniform pressure equal to $1000 \mathrm{~N} / \mathrm{m}$.

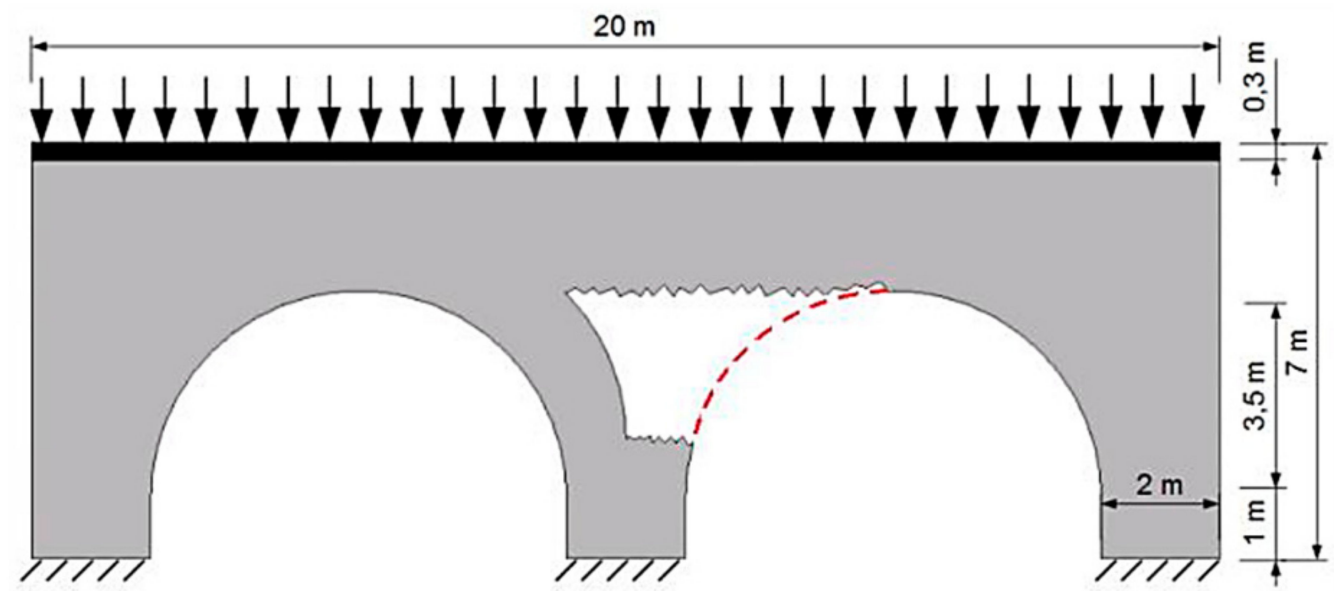

Figure 24. The initial damaged bridge structure with applied loads and supports. 
The structure is divided into two domains. The first one, a design-passive region, is presented in Figure 25, where grey color marks the weakened material. The designactive domain is marked red-in this domain, the strengthening is designed by topology optimization. For the first case, uniform material was selected for the whole structure (Young modulus E $=27 \times 10^{9} \mathrm{~Pa}$, Poisson ratio $v=0.3$ and density $\rho=2500 \mathrm{~kg} / \mathrm{m}^{3}$ ), and then the randomly weakened material was selected for the design-passive region to model a material degradation in the damaged construction. The material's random properties were calculated from the interval: $0.8 \times 27 \times 10^{9} \mathrm{~Pa}-27 \times 10^{9} \mathrm{~Pa}$ and $0.8 \times 2500 \mathrm{~kg} / \mathrm{m}^{3}-$ $2500 \mathrm{~kg} / \mathrm{m}^{3}$. These material uncertainties may serve as a simplified model of real-life material of old structures, for which it is impossible to describe material characteristics at every point without detailed examination.

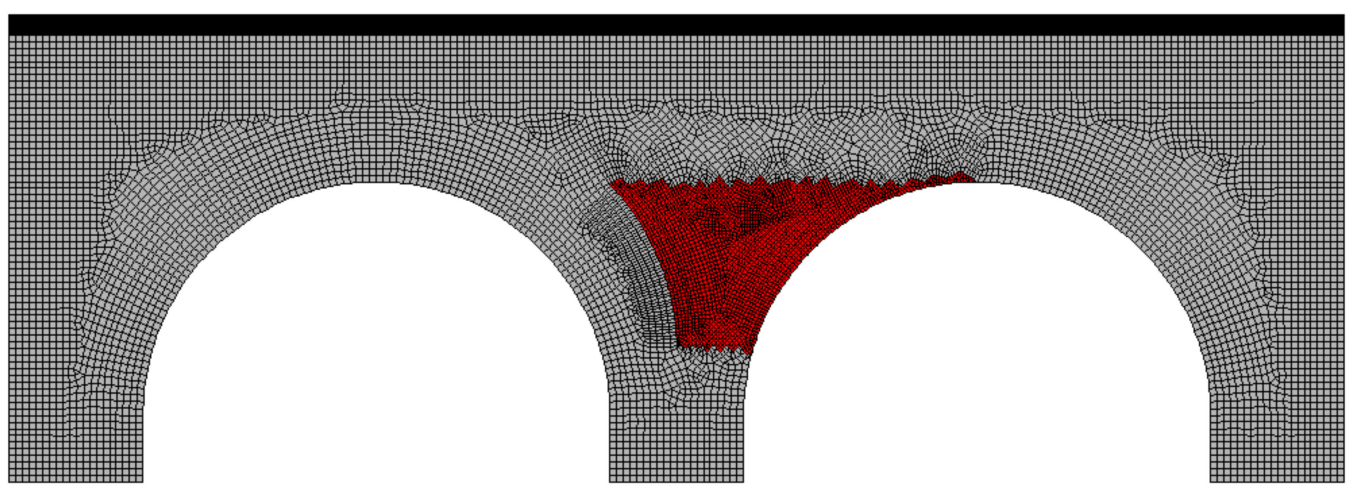

Figure 25. The domain subject to optimization—marked red.

The calculations for uniformly distributed material were performed first, which allowed for reducing the compliance value from $3.006 \times 10^{-2} \mathrm{Nm}$ for the initial structure (without strengthening) to $1.871 \times 10^{-2} \mathrm{Nm}$ for a structure with strengthening (see Figure 26a). At the same time, the maximum displacement was reduced from $0.315 \times 10^{-5} \mathrm{~m}$ to $0.150 \times 10^{-5} \mathrm{~m}$. The calculations for random weakness of the material were performed next, and as the result, the initial value of compliance of the structure, $3.334 \times 10^{-2} \mathrm{Nm}$, was reduced to $2.061 \times 10^{-2} \mathrm{Nm}$ (see Figure 26b). At the same time, the maximum displacement was reduced from $0.348 \times 10^{-5} \mathrm{~m}$ to $0.164 \times 10^{-5} \mathrm{~m}$. What is worth underlining is that the volumes of the strengthening for both cases are the same (volume fraction $\mathrm{k}$ for both cases equals 0.25 ).

As it was shown preliminarily in [49], the proposed approach can be an effective tool for designing the strengthening of damaged structures in the case of weakened material. In the present study, the self-weight loading has been taken into account, and the illustration of the influence of the self-weight on the final topologies is presented in Figure 27.

First, the calculations including self-weight for uniformly distributed material were performed, which allowed the compliance value to be reduced from $162 \mathrm{Nm}$ for the initial structure to $109 \mathrm{Nm}$ for a structure with strengthening (see Figure 27a). At the same time, the maximum displacement was reduced from $0.211 \times 10^{-3} \mathrm{~m}$ to $0.105 \times 10^{-3} \mathrm{~m}$. Next, the calculations for a random weakness of the material including self-weight were performed, and the initial value of compliance of the structure $144 \mathrm{Nm}$ was reduced to $100 \mathrm{Nm}$ (see Figure 27b). At the same time, maximum displacement was reduced from $0.221 \times 10^{-3} \mathrm{~m}$ to $0.104 \times 10^{-3} \mathrm{~m}$.

For example, as presented in Figure 26a, 60 iterations (about $5 \mathrm{~min}$.) were needed to reach a convergence, while for the example presented in Figure 26b, 80 (about $7 \mathrm{~min}$.). The iteration history showing the convergence to the final solution is provided in Figures 28 and 29. 


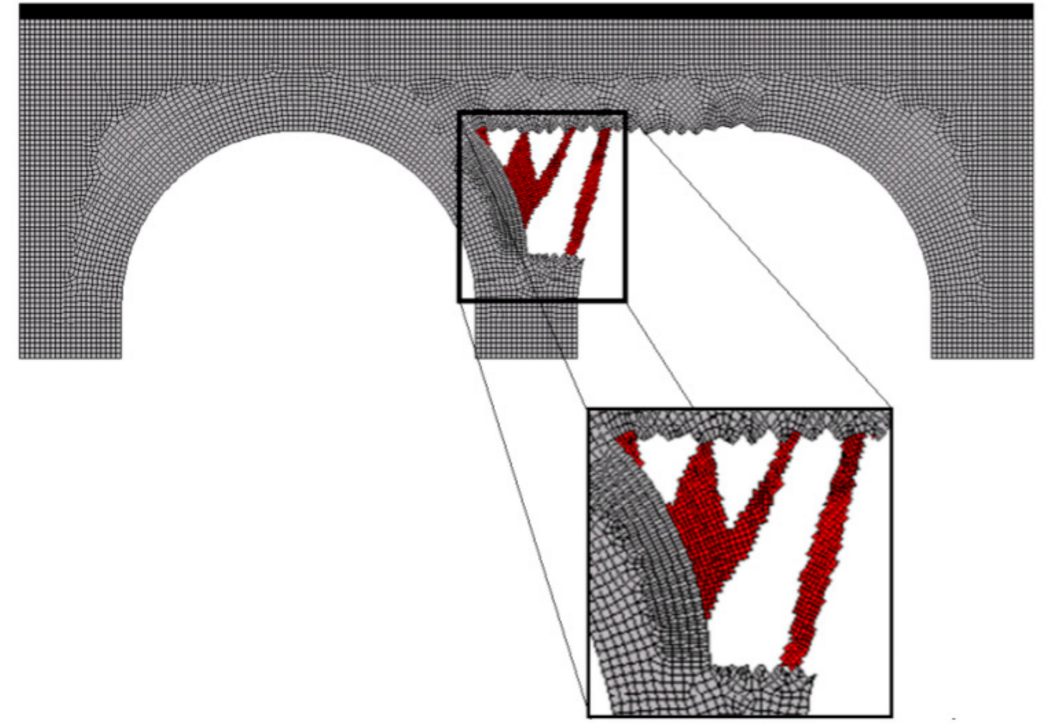

(a)

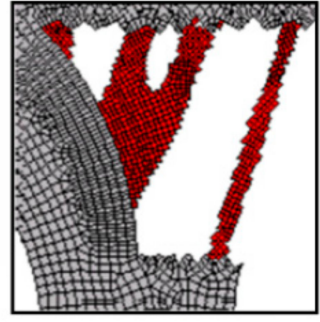

(b)

Figure 26. (a) The final topology of strengthening for uniformly distributed weakened material, (b) the final topology of strengthening random distribution of the Young modulus of weakened material. The magnification of the design-active region is applied.

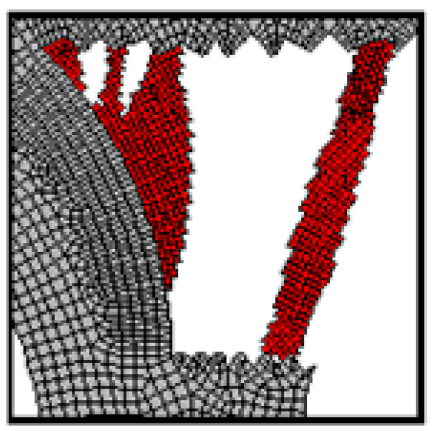

(a)

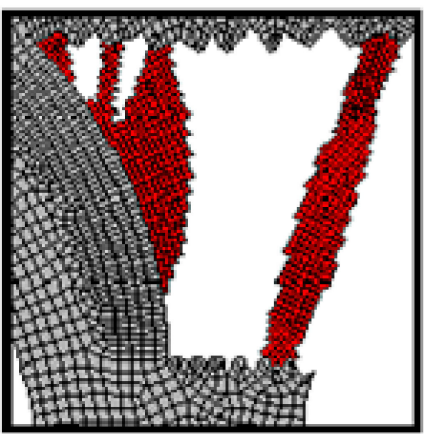

(b)

Figure 27. (a) The final topology of strengthening for uniformly distributed weakened material including self-weight; (b) the final topology of strengthening random distribution of the Young modulus of weakened material including self-weight. The magnification of the design-active region is applied.

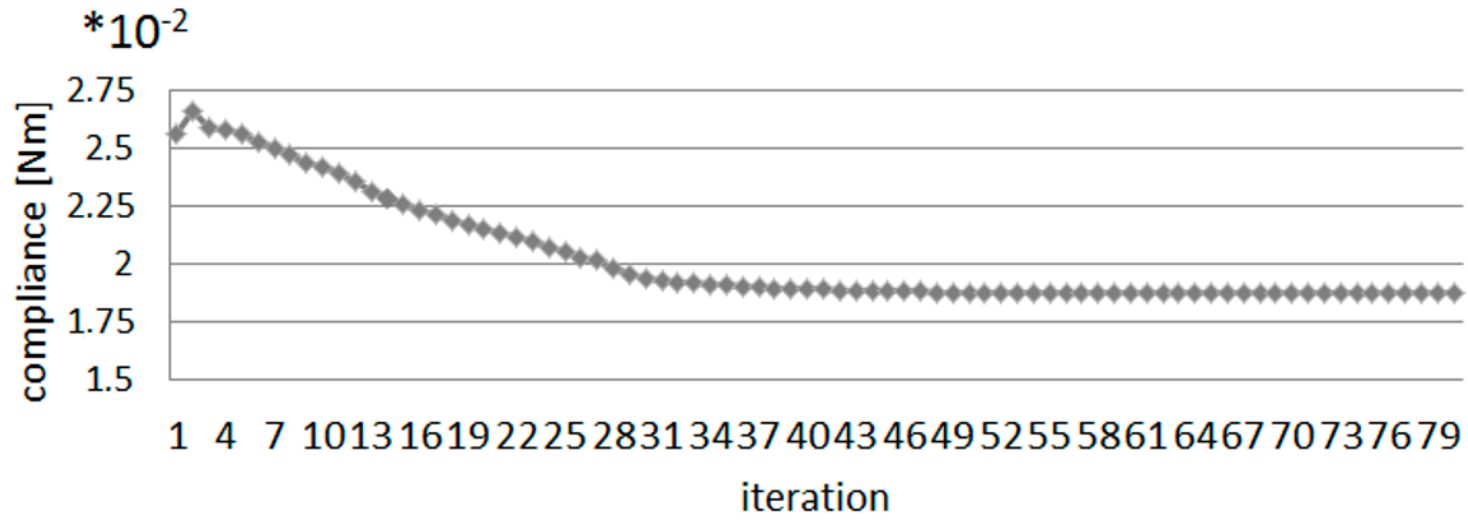

Figure 28. The iteration history for a topology presented in Figure 26a. 


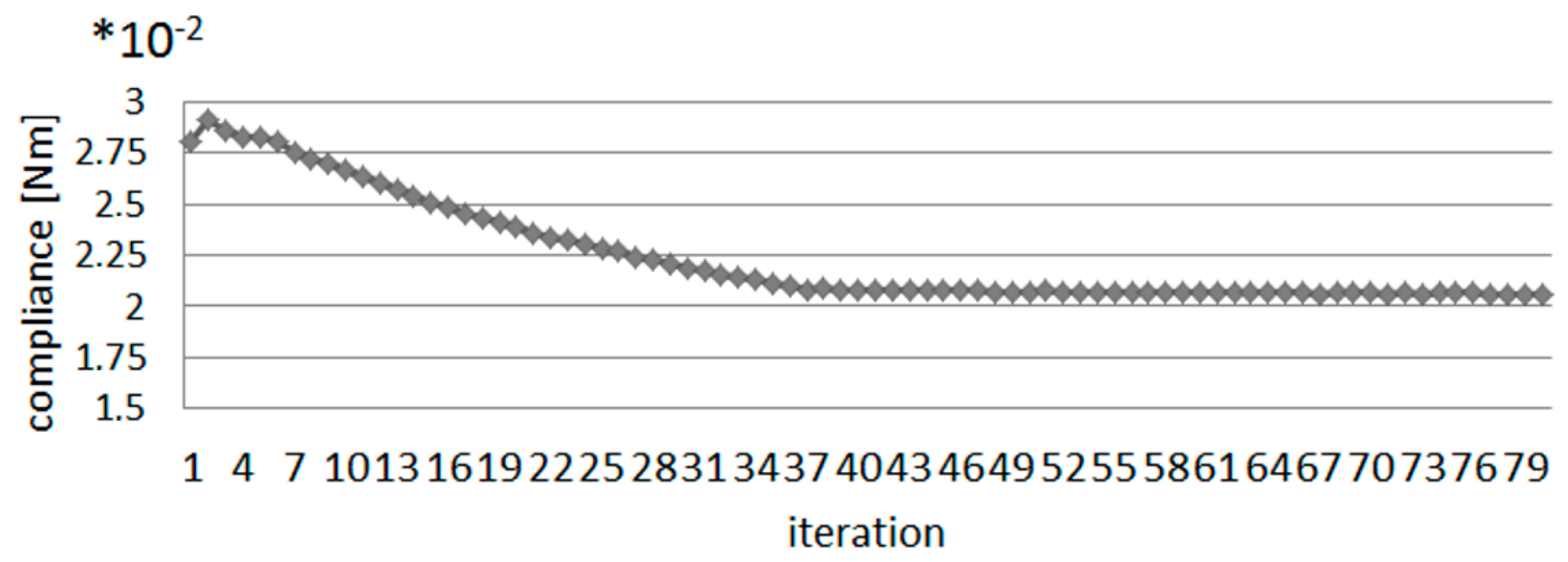

Figure 29. The iteration history for a topology presented in Figure 26b.

For examples where the self-weight loading is applied, 80 (i.e., about $7 \mathrm{~min}$ ) and 50 (i.e., about $4 \mathrm{~min}$ ) iterations were needed to reach the convergence. The iteration history showing the convergence to the final solution is provided in Figures 30 and 31 (for topologies presented in Figure 27a,b, respectively).

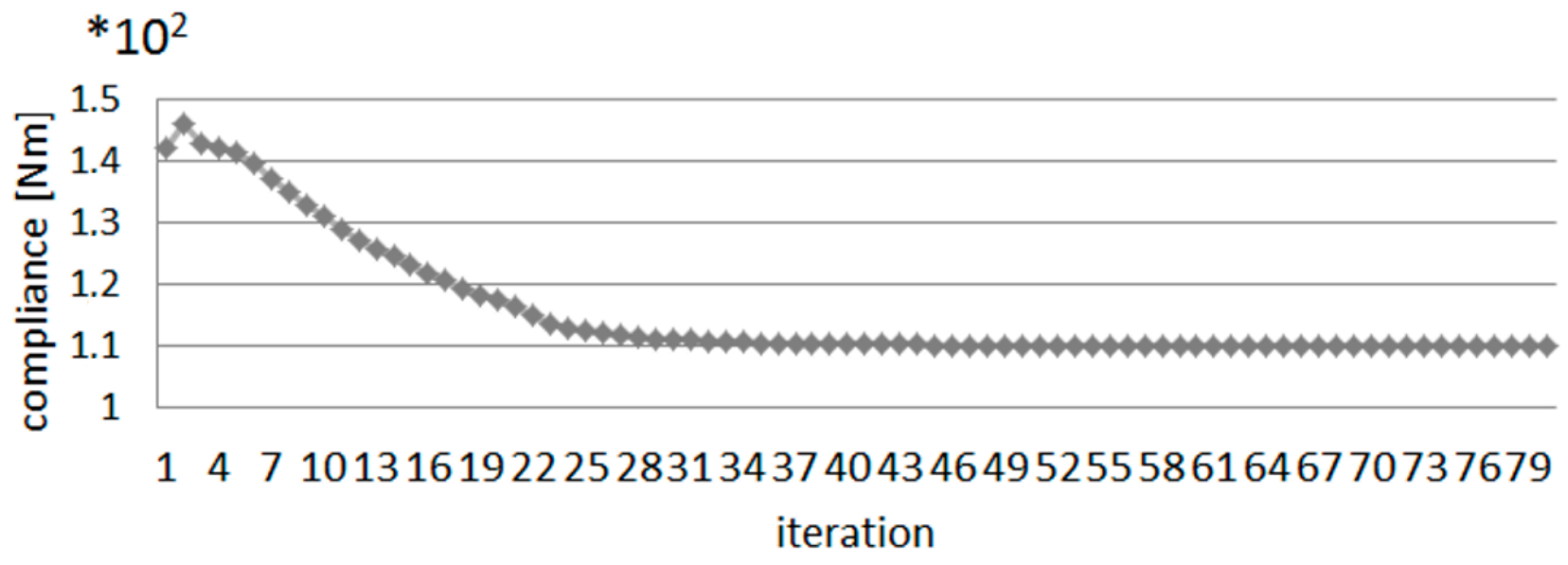

Figure 30. The iteration history for a topology presented in Figure 27a.

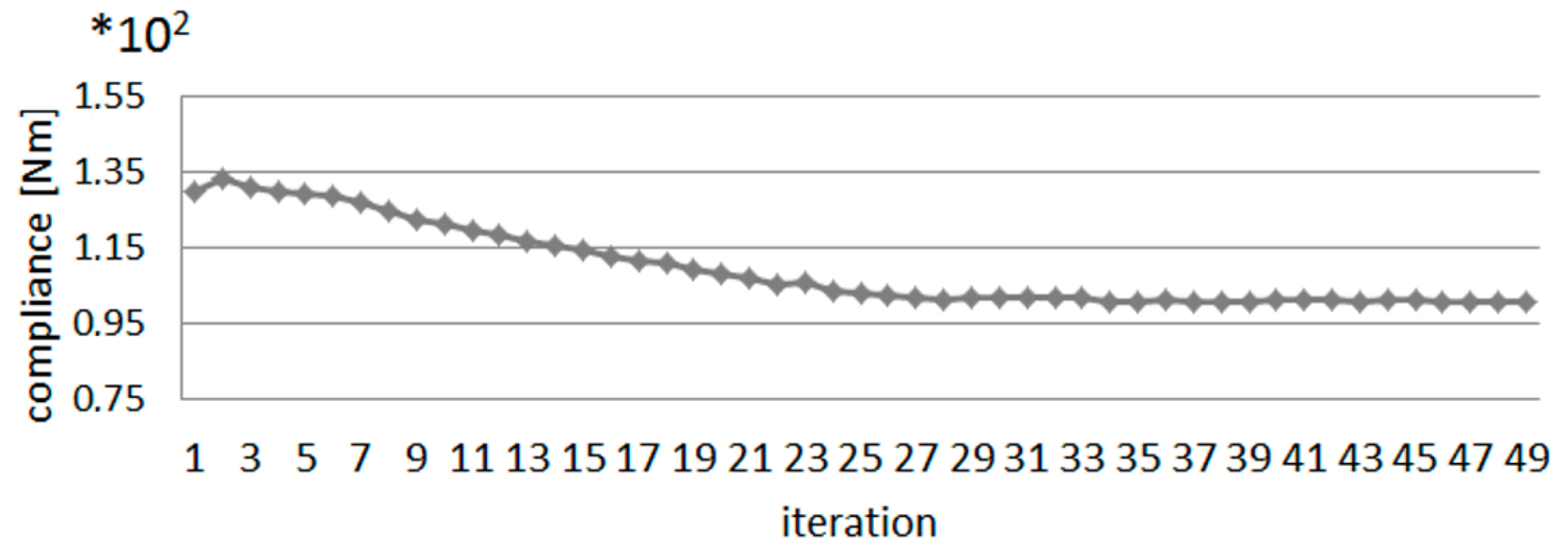

Figure 31. The iteration history for a topology presented Figure $27 \mathrm{~b}$. 
An interesting observation is that the final topology for examples for which the selfweight was included is almost the same. The explanation can be found in the ratio of values of external loadings and self-weight: when the self-weight is applied and the external forces are low compared to it, the distribution of the material is governed by its own weight more than by external loads transmitted through the weakened material to the design area.

\subsection{Strengthening of Structures Suffering from the Structural Damage-The Multiple-Load Case}

As an example of strengthening civil structures suffering from the effects of structural damage, a model of a building facade is proposed (see Figure 32). The idea is to use the given material amount to build the strengthenings, which can minimize the compliance of the stucture. To illustrate the versatility of the method, a multiple-load case is investigated. The loading cases are presented in Figure 33. The loading models wind loads and a snow load. The horizontal pressure equals $600 \mathrm{~N} / \mathrm{m}$, and the vertical load is distributed, as is shown in Figure 33c, equal to 7000 N.

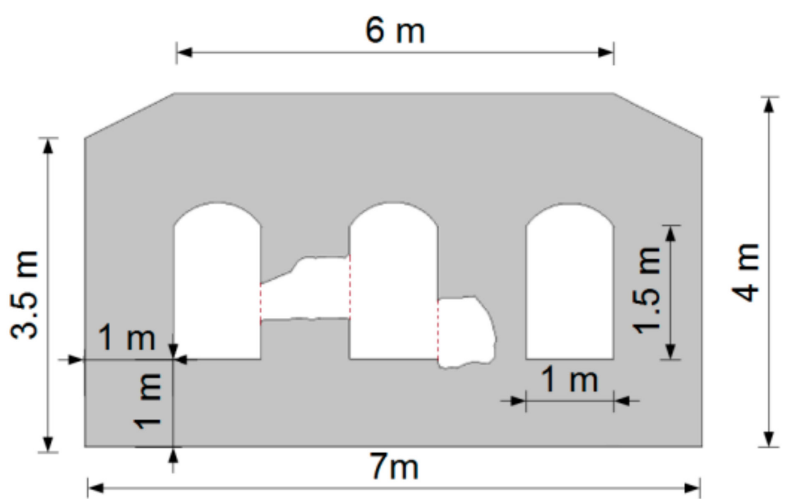

Figure 32. The damaged facade structure.

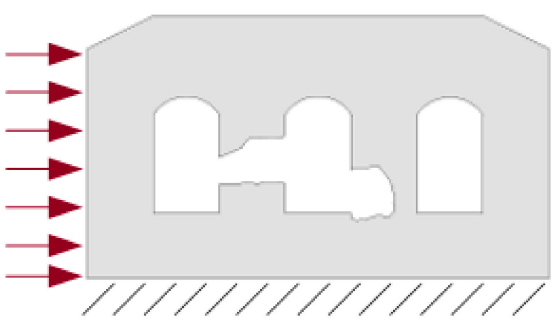

(a)

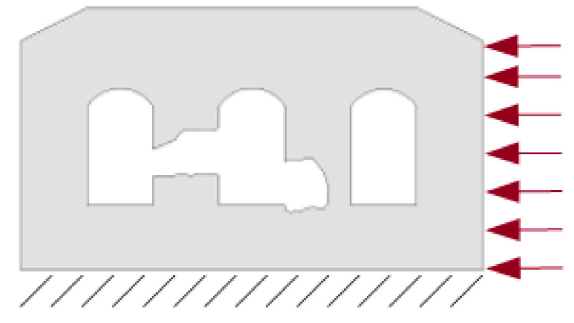

(b)

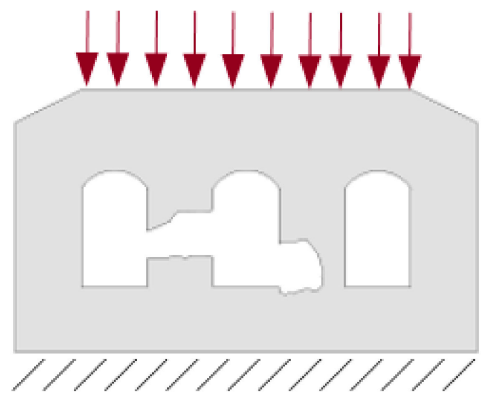

(c)

Figure 33. The damaged facade structure with applied load cases and supports: (a) load case I, (b) load case II, (c) load case III.

The applied material data are the Young modulus $\mathrm{E}=2 \times 10^{10} \mathrm{~Pa}$, the Poisson ratio $v=0.3$. In these cases, the material data are the same for the structure and the strengthening. The volume fraction $\mathrm{k}$ for all cases for design-active regions equals 0.2 . Figure 34 presents the final topologies for all schemes of loading treated separately and, at the end, the final topology for a multiple-load case. The magnification of the design-active region is applied.

The final values of compliances are, for the final topology for load case I, $6.133 \times$ $10^{-4} \mathrm{Nm}$; for the final topology for load case II, $6.262 \times 10^{-4} \mathrm{Nm}$; for the final topology for load case III: $3.978 \times 10^{-3} \mathrm{Nm}$. Considering the multiple-load case, the compliance should be checked for final topology, but for every loading separately, and what follows, the compliance values for the considered load cases are $0.692 \times 10^{-3} \mathrm{Nm}, 0.676 \times 10^{-3} \mathrm{Nm}$ and $4.032 \times 10^{-2} \mathrm{Nm}$, respectively. 


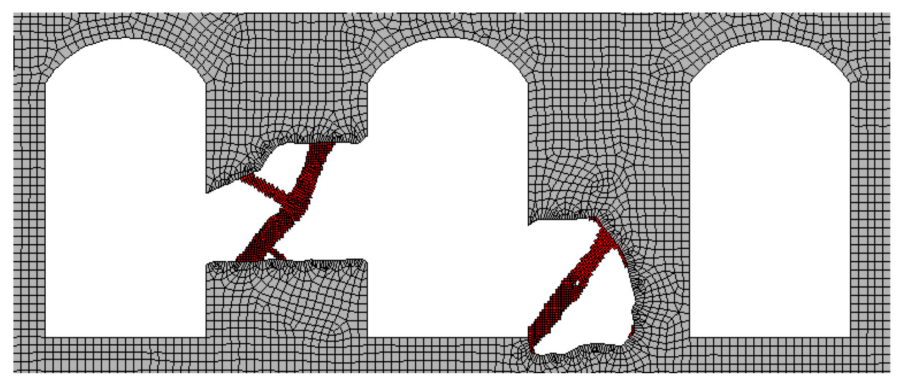

(a)

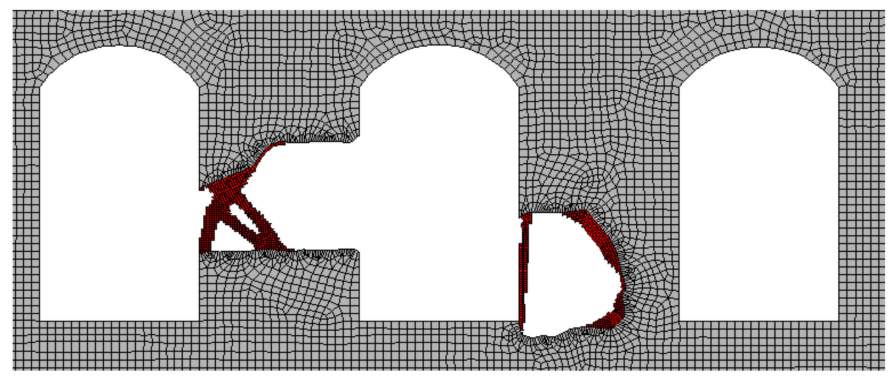

(b)

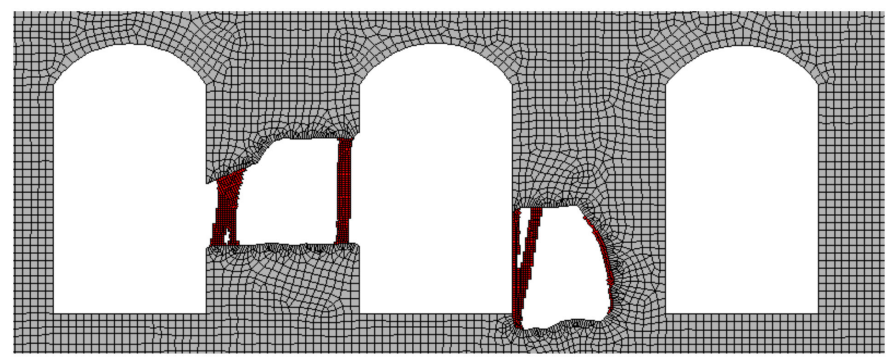

(c)

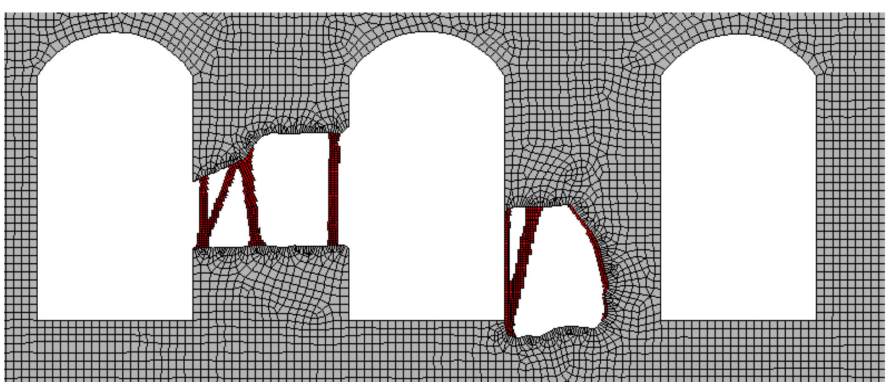

(d)

Figure 34. The final topologies for: (a) load case I, (b) load case II, (c) load case III, (d) load case IV (multiple-load case).

For this example, the convergence of the multiple-load case presented in Figure $34 \mathrm{~d}$ is discussed. At every iteration, three analyses are performed, so the computational time is larger than for the single-load case. For the presented example, 30 iterations were needed for the solution, which took about $9 \mathrm{~min}$ for 14,087 elements used for discretization. The iteration history showing the convergence to the final solution is provided in Figure 35. 


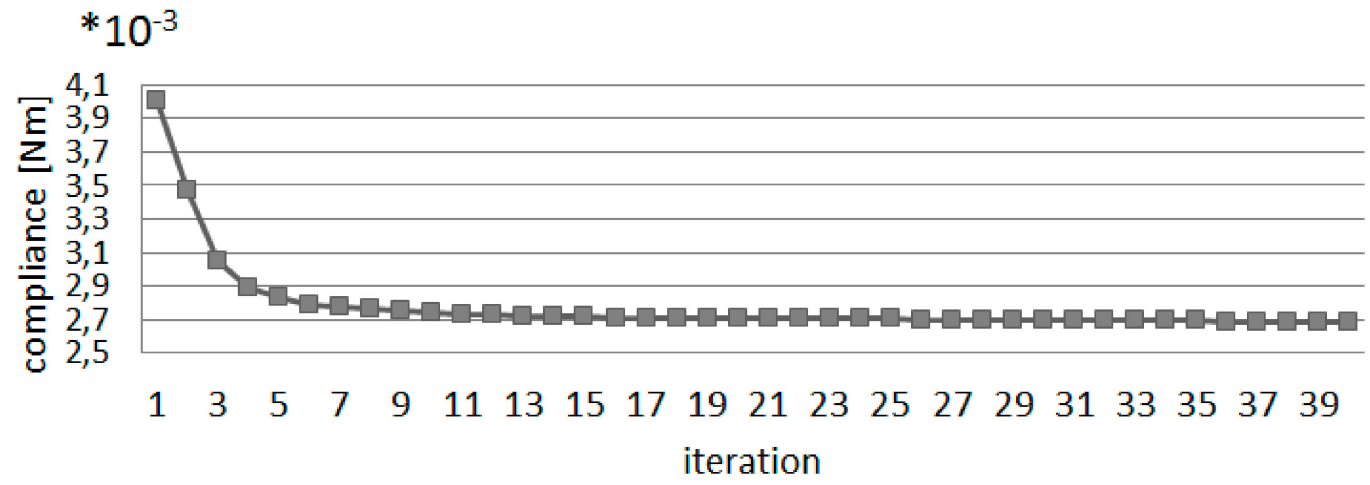

Figure 35. The iteration history for a topology presented in Figure 34d.

\subsection{Strengthening of the Multi-Material 3D Structures}

The strengthening of a multi-material 3D structure was selected to present the capabilities of the method in application to topology optimization for real three-dimensional engineering structures. The model of breach as a model of structural damage is presented in Figure 36, with the final strengthening (drawn in Figure 36 in red color). The material data for the strengthening was defined as $E_{1}=2 \times 10^{11} \mathrm{~Pa}$ and $v_{1}=0.3$, while the material data for the damaged structure (drawn in Figure 36 in grey color) was defined as $\mathrm{E}_{2}=2 \times 10^{10} \mathrm{~Pa}$ and $v_{2}=0.3$. The volume fraction was defined as 0.4 . The considered structure was divided into bottom $(1 \mathrm{~m} \times 0.5 \mathrm{~m} \times 0.1 \mathrm{~m})$ and top $(1 \mathrm{~m} \times 0.5 \mathrm{~m} \times 0.1 \mathrm{~m})$ blocks, determined as the non-optimized subdomains, and a middle block $(1 \mathrm{~m} \times 0.5 \mathrm{~m} \times$ $0.8 \mathrm{~m}$ ), determined as an optimized sub-domain. The bottom plane of the structure was fixed, while the top-right corner was loaded by three concentrated forces equal to $1000 \mathrm{~N}$ each, as presented in Figure 36. The initial compliance of the structure $4.990 \times 10^{-2} \mathrm{Nm}$ was reduced by the optimization process to the value of $2.511 \times 10^{-2} \mathrm{Nm}$.

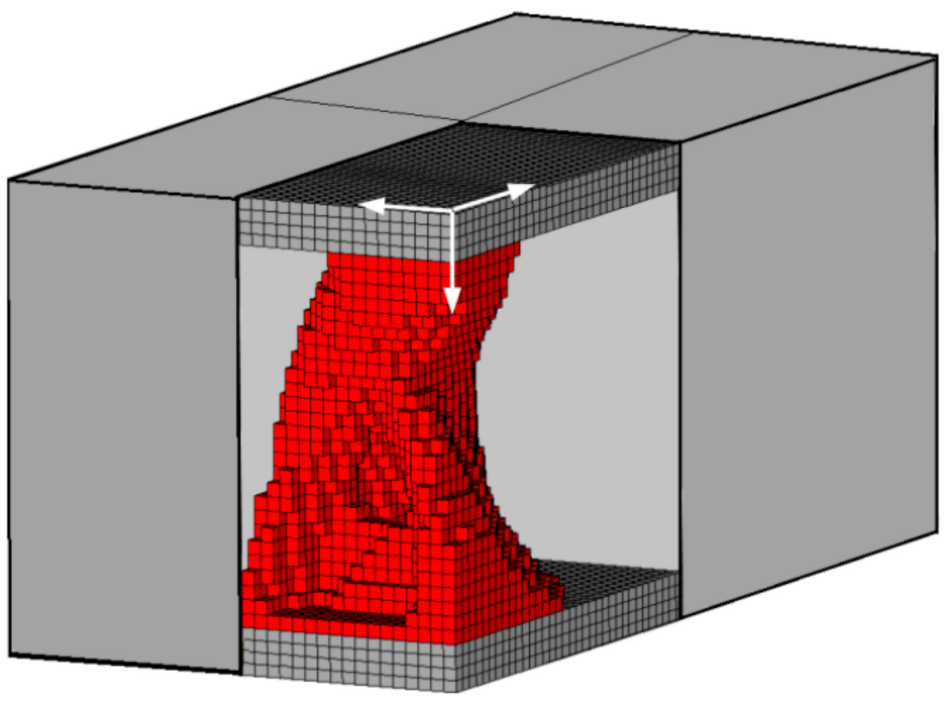

Figure 36. The final topology of the 3D structure strengthening.

For the 3D example, a quarter of a structure was considered with 20,230 elements. A total of 30 iterations were needed to get the solution, which took about $8 \mathrm{~min}$. The iteration history showing the convergence to the final solution is provided in Figure 37. 


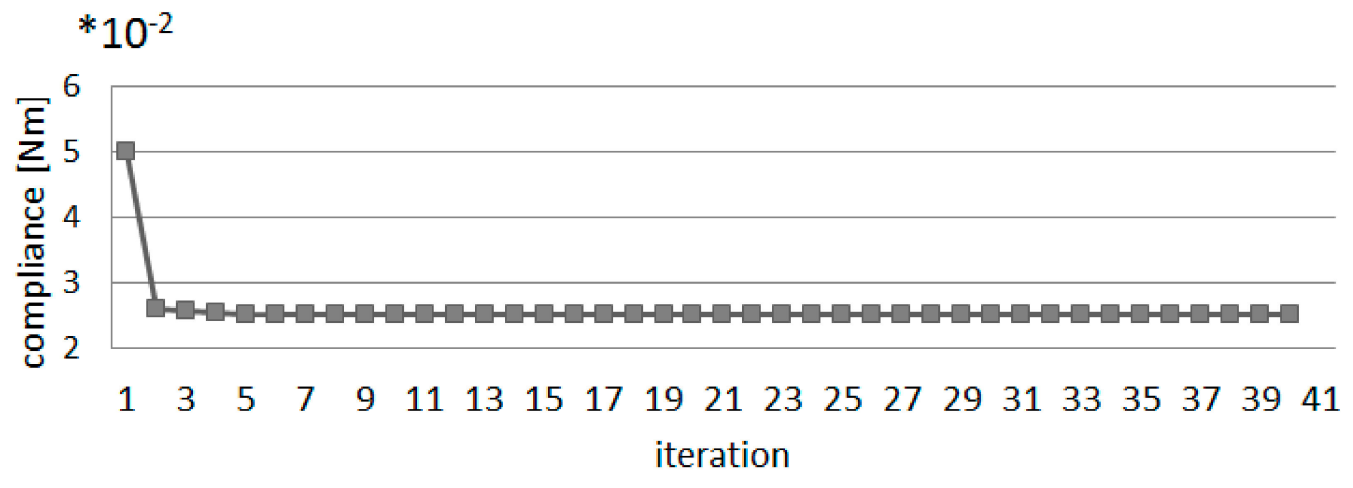

Figure 37. The iteration history.

\section{Discussion and Conclusions}

This paper presents the idea of sub-domain-based topology optimization of multimaterial structures under both external and self-weight loading. The design domain is divided into sub-regions, for which materials with different properties are applied. This approach to topology optimization allows one to obtain minimal-compliance structures with less material compared to the initial design. As has been shown, introducing a bimaterial structure leads to different results when compared to the problem formulated for uni-material structure. On the other hand, the distribution of material within a subdomain allows for this concept to be applied to architectural design, while multi-material solutions are desirable in innovative sustainable buildings to make constructions more environmentally friendly and modern. Furthermore, designers can be more flexible during the design process, with the possibility of using standard building material and new alternative solutions like renewable materials. The main issue, which can be a challenge in designing massive structures using topology optimization, is the implementation of the design-dependent loading, namely self-weight loading. In many cases, when applying optimization algorithms, numerical instabilities occur. The chosen method allows manufacturefriendly designs to be obtained easily and in a short calculation time, even when dealing with materials of different physical properties. Additionally, the proposed method is utilized for the sub-domain optimal design of strengthening of structures suffering from structural damage and/or material degradation. Material uncertainties, design-dependent loading (self-weight) and a multiple-load case are considered to illustrate the versatility of the method and the possibility of defining more complicated problems. What is very important is that the concept topology optimization performed by Cellular Automata is a fast-converged technique, not suffering from the checkerboard and mesh dependency effect. This method can be successfully used in practical civil engineering problems.

Author Contributions: Conceptualization, B.B. and K.T.-Z.; methodology, B.B. and K.T.-Z.; software, B.B. and K.T.-Z.; validation, B.B. and K.T.-Z.; formal analysis, B.B. and K.T.-Z.; investigation, B.B. and K.T.-Z.; resources, B.B. and K.T.-Z.; data curation, B.B. and K.T.-Z.; writing-original draft preparation, B.B. and K.T.-Z.; writing-review and editing, B.B. and K.T.-Z.; visualization, B.B. and K.T.-Z.; supervision, B.B. and K.T.-Z.; All authors have read and agreed to the published version of the manuscript.

Funding: This research was funded by the Faculty of Mechanical Engineering Cracow University of Technology.

Institutional Review Board Statement: Not applicable.

Informed Consent Statement: Not applicable.

Data Availability Statement: All files including APDL and FORTRAN code utilizing in this paper and data used to support the findings of this study are available from the corresponding author upon request. 
Conflicts of Interest: The authors declare no conflict of interest. The funders had no role in the design of the study; in the collection, analyses, or interpretation of data; in the writing of the manuscript, or in the decision to publish the results.

\section{References}

1. Bendsoe, M.P. Optimal shape design as a material distribution problem. Struct. Optim. 1989, 1, 193-202. [CrossRef]

2. Sigmund, O. A 99 line topology optimization code written in MATLAB. Struct. Multidiscip. Optim. 2001, 21, 120-127. [CrossRef]

3. Andreassen, E.; Clausen, A.; Schvenels, M.; Lazarov, B.S.; Sigmund, O. Efficient topology optimization in Matlab using 88 lines of code. Struct. Multidiscip. Optim. 2011, 4,1-16. [CrossRef]

4. Liu, K.; Tovar, A. An efficient 3D topology optimization code written in Matlab. Struct. Multidiscip. Optim. 2014, 50, 1175-1196. [CrossRef]

5. Xie, X.M.; Steven, G.P. Evolutionary Structural Optimisation; Springer: Berlin, Germany, 1997.

6. Querin, Q.M.; Steven, G.P.; Xie, Y.M. Evolutionary structural optimization using a bi-directional algorithm. Eng. Comput. 1998, 15, 1034-1048. [CrossRef]

7. Kane, C.; Jouve, F.; Schoenauer, M. Structural topology optimization in linear and nonlinear elasticity using genetic algorithms. In Proceedings of the 21st ASME Design Automatic Conference, Boston, MA, USA, 17-20 September 1995; pp. 1-8.

8. Balamurugan, R.; Ramakrishnan, C.; Singh, N. Performance evaluation of a two stage adaptive genetic algorithm in structural topology optimization. Appl. Soft Comput. 2008, 8, 1607-1624. [CrossRef]

9. Kaveh, A.; Hassani, B.; Shojaee, S.; Tavakkoli, S.M. Structural topology optimization using ant colony methodology. Eng. Struct. 2008, 30, 2559-2565. [CrossRef]

10. Kobayashi, M.H. On a biologically inspired topology optimization method. Commun. Nonlinear Sci. Numer. Simul. 2010, 15, 787-802. [CrossRef]

11. Chang, S.Y.; Youn, S.K. Material cloud method for topology optimization. Numer. Methods Eng. 2006, 65, 1585-1607. [CrossRef]

12. Eschenauer, H.A.; Kobelev, V.V.; Schumacher, A. Bubble method for topology and shape optimization of structures. Struct. Optim. 1993, 8, 42-51. [CrossRef]

13. Wang, M.Y.; Wang, X.; Guo, D. A level set method for structural topology optimization. Comput. Methods Appl. Mech. Eng. 2003, 192, 227-246. [CrossRef]

14. Allaire, G.; Jouve, F.; Toader, A.M. Structural optimization using sensitivity analysis and a level-set method. J. Comput. Phys. 2004, 194, 363-393. [CrossRef]

15. Otomori, M.; Yamada, T.; Izui, K.; Nishiwaki, S. Matlab code for a level set-based topology optimization method using a reaction diffusion equation. Struct. Multidiscip. Optim. 2015, 51, 1159-1172. [CrossRef]

16. Wei, P.; Li, Z.; Li, X.; Wang, M.Y. An 88-line MATLAB code for the parameterized level set method based topology optimization using radial basis functions. Struct. Multidiscip. Optim. 2018, 58, 831-849. [CrossRef]

17. Biyikli, E.; To, A.C. Proportional topology optimization: A new non-sensitivity method for solving stress constrained and minimum compliance problems and its implementation in Matlab. PLoS ONE 2015, 10, e0145041. [CrossRef]

18. Guo, X.; Zhang, W.S.; Zhong, W.L. Doing topology optimization explicitly and geometrically-A new moving morphable components based framework. J. Appl. Mech. 2014, 81, 081009. [CrossRef]

19. Zhang, W.; Yuan, J.; Zhang, J.; Guo, X. A new topology optimization approach based on Moving Morphable Components (MMC) and the ersatz material model. Struct. Multidiscip. Optim. 2016, 53, 1243-1260. [CrossRef]

20. Gao, J.; Xue, H.; Gao, L.; Luo, Z. Topology optimization for auxetic metamaterials based on isogeometric analysis. Comput. Methods Appl. Mech. Engrg. 2019, 352, 211-236. [CrossRef]

21. Xu, J.; Gao, L.; Xiao, M.; Xu, J.; Li, H. Isogeometric topology optimization for rational design of ultra-lightweight architected materials. Int. J. Mech. Sci. 2020, 166, 105103. [CrossRef]

22. Gao, J.; Xiao, M.; Gao, L.; Yan, J.; Yan, W. Isogeometric topology optimization for computational design of re-entrant and chiral auxetic composites. Comput. Methods Appl. Mech. Engrg. 2020, 362, 112876. [CrossRef]

23. Gao, J.; Luo, Z.; Xiao, M.; Gao, L.; Li, P. A NURBS-based Multi-Material Interpolation (N-MMI) for isogeometric topology optimization of structures. Appl. Math. Model. 2020, 81, 818-843. [CrossRef]

24. Sigmund, O.; Maute, K. Topology optimization approaches. Struct. Multidiscip. Optim. 2013, 48, 1031-1055. [CrossRef]

25. Deaton, J.D.; Grandhi, R.V. A survey of structural and multidisciplinary continuum topology optimization: Post 2000. Struct. Multidiscip. Optim. 2014, 49, 1-38. [CrossRef]

26. Sajjad Zargham, S.; Thomas Arthur Ward, T.A.; Rahizar Ramli, R.; Irfan Anjum Badruddin, I.A. Topology optimization: A review for structural designs under vibration problems. Struct. Multidiscip. Optim. 2016, 53, 1157-1177. [CrossRef]

27. Liu, J.; Gaynor, A.T.; Chen, S.; Kang, Z.; Suresh, K.; Takezawa, A.; Li, L.; Kato, J.; Tang, J.; Wang, C.C.L.; et al. Current and future trends in topology optimization for additive manufacturing. Struct. Multidiscip. Optim. 2018, 57, 2457-2483. [CrossRef]

28. $\mathrm{Wu}, \mathrm{J} . ; \mathrm{Wu}, \mathrm{L}$. Revised level set-based method for topology optimization and its applications in bridge construction. Open Civ. Eng. J. 2017, 11, 153-166. [CrossRef]

29. Xie, Y.; Zuo, Z.; Huang, X.; Black, T.; Felicetti, P. Application of topological optimization technology to bridge design. Struct. Eng. Int. 2014, 24, 185-191. 
30. Beghini, L.; Beghini, A.; Katz, N.; Baker, W.; Paulino, G. Connecting architecture and engineering through structural topology optimization. Eng. Struct. 2014, 59, 716-726. [CrossRef]

31. Kingman, J.; Tsavdaridis, K.; Toropov, V. Applications of topology optimization in structural engineering: High-rise buildings and steel components. Jordan J. Civ. Eng. 2015, 9, 335-357.

32. Dapogny, C.; Faure, A.; Michailidis, G.; Allaire, G.; Couvelas, A.; Estevez, R. Geometric constraints for shape and topology optimization in architectural design. Comput. Mech. 2017, 59, 933-965. [CrossRef]

33. Aage, N.; Amir, O.; Clausen, A.; Hadar, L.; Maier, D.; Sondergaard, A. Advanced topology optimization methods for conceptual architectural design. In Advances in Architectural Geometry; Block, P., Knippers, J., Mitra, N., Wang, W., Eds.; Springer: Berlin, Germany, 2014.

34. Syngellakis, S. (Ed.) Retrofitting of Heritage Structures. Design and Evaluation of Strengthening Technique; WIT Press: Southampton, UK, 2016; p. 62.

35. Costa, A.; Arêde, A.; Varum, H. (Eds.) Strengthening and Retrofitting of Existing Structures; Springer: Singapore, 2018.

36. Bel Hadj Ali, N.; Rhode-Barbarigos, L.; Pascual Albi, A.A.; Smith, I.F.C. Design optimization and dynamic analysis of a tensegrity-based footbridge. Eng. Struct. 2010, 32, 3650-3659. [CrossRef]

37. Montuori, R.; Skelton, R.E. Globally stable tensegrity compressive structures for arbitrary complexity. Compos. Struct. 2017, 179, 682-694. [CrossRef]

38. Rozvany, G.I.N. Optimal plastic design: Allowance for self-weight. J. Eng. Mech. Div. 1977, 103, 1165-1170. [CrossRef]

39. Bruyneel, M.; Duysinx, P. Note on topology optimization of continuum structures including self-weight. Struct. Multidiscip. Optim. 2005, 29, 245-256. [CrossRef]

40. Zhang, H.; Liu, S.; Xiong, Z. Topology optimization of 3d structures with design-dependent loads. Acta Mech. Sin. 2010, 26, 767-775. [CrossRef]

41. Chen, B.C.; Kikuchi, N. Topology optimization with design-dependent loads. Finite Elem. Anal. Des. 2001, 37, 57-70. [CrossRef]

42. Zhou, M.; Rozvany, G.I.N. The COC algorithm, Part II: Topological, geometry and generalized shape optimization. Comput. Methods Appl. Mech. Eng. 1991, 89, 197-224. [CrossRef]

43. Felix, L.; Gomes, A.; Suleman, A. Wing topology optimization with self-weight loading. In Proceedings of the 10th World Congress on Structural and Multidisciplinary Optimization, Orlando, FL, USA, 19-24 May 2013; Furnish, M.D., Ed.;

44. Tajs-Zielińska, K.; Bochenek, B. Topology Optimization-Engineering Contribution to Architectural Design. Iop Conf. Ser. Mater. Sci. Eng. 2017, 245, 082057. [CrossRef]

45. Peraza-Hernandez, E.A.; Hartl, D.J.; Malak, R.J., Jr.; Lagoudas, D.C. Origami-inspired active structures: A synthesis and review. Smart Mater. Struct. 2014, 23, 094001. [CrossRef]

46. Farzampour, A.; Khatibinia, M.; Mansouri, I. Shape optimization of butterfly-shaped shear links using Grey Wolf algorithm. Ing. Sism. 2019, 36, 27-41.

47. Tajs-Zielińska, K.; Bochenek, B. CARMA-Cellular Automata with Refined Mesh Adaptation-The Easy Way of Generation of Structural Topologies. Appl. Sci. 2020, 10, 3691. [CrossRef]

48. Bochenek, B.; Tajs-Zielińska, K. Novel local rules of cellular automata applied to topology and size optimization. Eng. Optim. 2012, 44, 23-35. [CrossRef]

49. Tajs-Zielinska, K.; Bochenek, B. Novel Topology Optimization Techniques Adapted to Strengthening of Civil Structures Suffering from the Effects of Material Degradation. Iop Conf. Ser. Mater. Sci. Eng. 2019, 471, 052010. [CrossRef] 